\title{
Intercomparison of atmospheric water vapour measurements at a Canadian High Arctic site
}

\author{
Dan Weaver ${ }^{1}$, Kimberly Strong ${ }^{1}$, Matthias Schneider ${ }^{2}$, Penny M. Rowe ${ }^{3,4}$, Chris Sioris ${ }^{5}$, Kaley A. Walker ${ }^{1,6}$, \\ Zen Mariani $^{7}$, Taneil Uttal ${ }^{8}$, C. Thomas McElroy ${ }^{5}$, Holger Vömel ${ }^{9}$, Alessio Spassiani ${ }^{10}$, and James R. Drummond ${ }^{11}$ \\ ${ }^{1}$ Department of Physics, University of Toronto, Toronto, Ontario, Canada \\ ${ }^{2}$ Institute of Meteorology and Climate Research (IMK-ASF), Karlsruhe Institute of Technology, Karlsruhe, Germany \\ ${ }^{3}$ NorthWest Research Associates, Redmond, Washington, USA \\ ${ }^{4}$ Department of Physics, Universidad de Santiago de Chile, Santiago, Chile \\ ${ }^{5}$ Department of Earth and Space Science and Engineering, York University, Toronto, Canada \\ ${ }^{6}$ Department of Chemistry, University of Waterloo, Waterloo, Ontario, Canada \\ ${ }^{7}$ Cloud Physics and Severe Weather Research Section, Environment and Climate Change Canada, Toronto, Ontario, Canada \\ ${ }^{8}$ Earth Systems Research Laboratory, National Oceanic and Atmospheric Administration, Boulder, Colorado, USA \\ ${ }^{9}$ Earth Observing Laboratory, National Center for Atmospheric Research, Boulder, Colorado, USA \\ ${ }^{10}$ School of Civil Engineering, University of Queensland, Brisbane, Australia \\ ${ }^{11}$ Department of Physics and Atmospheric Science, Dalhousie University, Halifax, Nova Scotia, Canada
}

Correspondence to: Dan Weaver (dweaver@atmosp.physics.utoronto.ca)

Received: 4 October 2016 - Discussion started: 22 November 2016

Revised: 6 July 2017 - Accepted: 11 July 2017 - Published: 11 August 2017

\begin{abstract}
Water vapour is a critical component of the Earth system. Techniques to acquire and improve measurements of atmospheric water vapour and its isotopes are under active development. This work presents a detailed intercomparison of water vapour total column measurements taken between 2006 and 2014 at a Canadian High Arctic research site (Eureka, Nunavut). Instruments include radiosondes, sun photometers, a microwave radiometer, and emission and solar absorption Fourier transform infrared (FTIR) spectrometers. Close agreement is observed between all combination of datasets, with mean differences $\leq 1.0 \mathrm{~kg} \mathrm{~m}^{-2}$ and correlation coefficients $\geq 0.98$. The one exception in the observed high correlation is the comparison between the microwave radiometer and a radiosonde product, which had a correlation coefficient of 0.92 .

A variety of biases affecting Eureka instruments are revealed and discussed. A subset of Eureka radiosonde measurements was processed by the Global Climate Observing System (GCOS) Reference Upper Air Network (GRUAN) for this study. Comparisons reveal a small dry bias in the standard radiosonde measurement water vapour total columns of approximately $4 \%$. A recently produced solar ab-
\end{abstract}

sorption FTIR spectrometer dataset resulting from the MUSICA (MUlti-platform remote Sensing of Isotopologues for investigating the Cycle of Atmospheric water) retrieval technique is shown to offer accurate measurements of water vapour total columns (e.g. average agreement within $-5.2 \%$ of GRUAN and $-6.5 \%$ of a co-located emission FTIR spectrometer). However, comparisons show a small wet bias of approximately $6 \%$ at the high-latitude Eureka site. In addition, a new dataset derived from Atmospheric Emitted Radiance Interferometer (AERI) measurements is shown to provide accurate water vapour measurements (e.g. average agreement was within $4 \%$ of GRUAN), which usefully enables measurements to be taken during day and night (especially valuable during polar night).

\section{Introduction}

Water vapour plays a significant role in the Earth's atmosphere. It is involved in driving atmospheric dynamics (Hwang and Frierson, 2010) and actively impacts atmospheric chemistry (Shindell, 2001). Water vapour has a dom- 
inant effect on climate and radiative forcing (Soden et al., 2002; Dessler et al., 2008). Climate-change-induced shifts to the global hydrological cycle affect atmospheric transport processes, creating and intensifying droughts and flooding (Trenberth et al., 2013). Understanding the global water cycle has critical value, yet our understanding of water vapour's abundances, variability, and transport is incomplete (Stevens and Bony, 2013). Atmospheric models are not able to accurately and precisely represent the water cycle. More observations are the key to addressing this deficiency (Trenberth et al., 2014). Observations of the Arctic region are particularly sparse and important for understanding how the planet's atmosphere is changing (ACIA, 2005). This study compares measurements of atmospheric water vapour taken near Eureka, Nunavut, in the Canadian High Arctic.

The Arctic region is disproportionately affected by climate change. Temperatures in the Arctic have increased more than elsewhere on the planet. At Eureka, Nunavut $\left(80^{\circ} \mathrm{N}, 86^{\circ} \mathrm{W}\right)$, a research site in the Canadian High Arctic, surface temperatures increased by $0.88 \pm 0.17^{\circ} \mathrm{C}$ per decade between 1972 and 2007 (Lesins et al., 2010). This observed Arctic warming trend is expected to continue (IPCC, 2013). Alongside this warming, the total column of water vapour at Eureka increased by $10 \pm 3 \%$ between 1961 and 2007, according to radiosoundings (Lesins et al., 2010). Analysis of radiosonde (RS) water vapour total columns (below $500 \mathrm{hPa}$ ) from 1979 to 2008 by Serreze et al. (2012) also showed statistically significant positive trends at Eureka, with the largest increases during summer. This aligns with the expectation that water vapour abundances will increase globally as temperatures increase (Soden et al., 2002). In the High Arctic, the impact of this increase in atmospheric water vapour on the radiative balance (and thus climate) is particularly acute (Tobin et al., 1999).

Efforts are underway to improve and expand water vapour measurements. Space-based instruments with water vapour products, such as the Atmospheric Infrared Sounder (Aumann et al., 2003) and the Atmospheric Chemistry Experiment (ACE; Sheese et al., 2016; Sioris et al., 2010), provide (almost) global measurement coverage. However, obtaining sensitivity to the lower troposphere is challenging for satellites, and detailed studies of specific regions are temporally limited. Balloon-based and ground-based observation networks complement space-based observations. The Global Climate Observing System (GCOS) Reference Upper Air Network (GRUAN) enhances the scientific utility of highvertical-resolution meteorological balloon measurements; however, GRUAN is geographically limited. Additionally, most measurement sites launch radiosondes only twice daily. The MUlti-platform remote Sensing of Isotopologues for investigating the Cycle of Atmospheric water (MUSICA) project can contribute to this need for frequent high-quality water vapour measurements. MUSICA uses existing groundbased Network for the Detection of Atmospheric Composition Change (NDACC) Fourier transform infrared (FTIR) spectrometer observations to produce a precise and accurate measurement of water vapour isotopologues. Techniques for producing datasets from the high-quality measurements taken by NDACC FTIR instruments have been under active development for decades (e.g. Kurylo, 1991). MUSICA retrievals produce information about water vapour with reasonable measurement sensitivity throughout the troposphere as well as information about water vapour isotopologues in the lower and middle troposphere (Schneider et al., 2012, 2015). Multiple FTIR measurements are typically taken at measurement sites each day. These new observations of water vapour provide valuable opportunities for improving our understanding of the climate system and the water cycle.

This study compares atmospheric water vapour measurement techniques used at a research facility in the Canadian High Arctic located in Eureka, Nunavut. The goals of this study are to describe water vapour abundances near Eureka and assess the agreement between available datasets. Particular focus is placed on assessing the accuracy of a new Eureka 125HR FTIR dataset produced by the MUSICA retrieval technique and a new retrieval using an emission FTIR spectrometer.

This paper is structured as follows. Section 1 offers an introduction to the measurement site. Section 2 describes the instruments and datasets available at Eureka. These each involve distinct measurement techniques, the strengths and weaknesses of which will be considered. Section 3 compares the datasets and assesses how consistent they are with each other. Section 4 discusses the results of the intercomparisons. Section 5 offers conclusions about the ability of the Eureka datasets to capture information about High Arctic water vapour at Eureka and comments on possible future studies.

\subsection{Measurement site}

Eureka, Nunavut, is a small research community situated at $80^{\circ} \mathrm{N}$ in the remote polar desert of Ellesmere Island, Canada. It primarily exists to support Environment and Climate Change Canada's Eureka Weather Station (EWS) but also supports research programs led by universities, government agencies, and other organizations. The most significant of these is the Polar Environment Atmospheric Research Laboratory (PEARL), run by a group of Canadian universities through the Canadian Network for the Detection of Atmospheric Change (CANDAC). Until PEARL opened in 2006, the only information regularly gathered locally about atmospheric water vapour was obtained through the launch of radiosondes at the EWS. The suite of PEARL instruments has expanded the available information about the atmosphere above Eureka substantially. PEARL is strategically located for Arctic studies, as well as the validation of satellite measurements (e.g. Batchelor et al., 2010; Adams et al., 2012). Validating the accuracy of PEARL water vapour measurements thus has substantial value. 


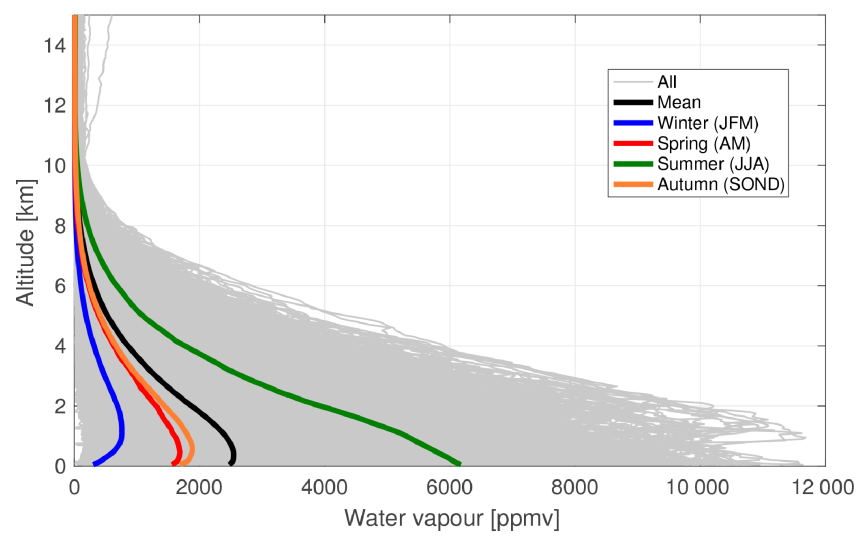

Figure 1. Eureka radiosonde water vapour profiles (August 2006 to December 2015). JFM: January-February-March; AM: AprilMay; JJA: June-July-August; SOND: September-December.

PEARL consists of multiple facilities. Instruments whose water vapour datasets are used for this study are located at the PEARL Ridge Lab (RL) and the zero-altitude PEARL Auxiliary Laboratory (OPAL). The Ridge Lab is located at $80.05^{\circ} \mathrm{N}, 86.4^{\circ} \mathrm{W}$ on top of a ridge at $610 \mathrm{~m}$ elevation, $15 \mathrm{~km}$ west of Eureka. OPAL is located in Eureka $\left(79.59^{\circ} \mathrm{N}\right.$, $\left.85.56^{\circ} \mathrm{W}\right)$ near sea level (10 m a.s.1.), approximately $250 \mathrm{~m}$ from the EWS radiosonde launch location. The Ridge Lab and OPAL sites often experience different local weather conditions (Fogal et al., 2013), which should be considered when assessing measurements taken at the RL and OPAL.

\subsection{Eureka water vapour}

Eureka is a challenging site for water vapour measurements. It is an extremely cold and dry environment. Between fall and spring, there are frequent temperature and humidity inversions in the lower troposphere. Open water occurs regionally during summer, but during the rest of the year the region's fjords and sounds are frozen. The surrounding geography is mountainous and variable. Solar-viewing measurements are often made at large solar zenith angles (SZAs), especially during spring and fall. It is not possible to use atmospheric measurement techniques that require sunlight during polar night, which lasts from mid-October until late February at Eureka's latitude. These conditions, along with the availability of several instruments located at two different altitudes, offer the opportunity to investigate the effectiveness of different measurement techniques.

The Eureka radiosonde dataset has informed weather research for over 50 years and offers useful information about water vapour abundances and variability near Eureka. Figure 1 shows radiosonde water vapour profiles recorded between August 2006 and December 2015, along with overall and seasonal mean profiles (Eureka radiosonde measurements are described in more detail in Sect. 2.4). The definition of seasons is atypical, with a short spring (April-May) (a)

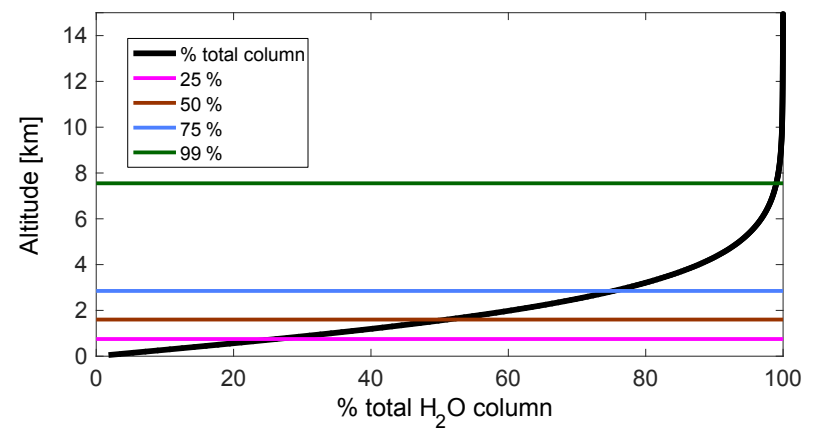

(b)

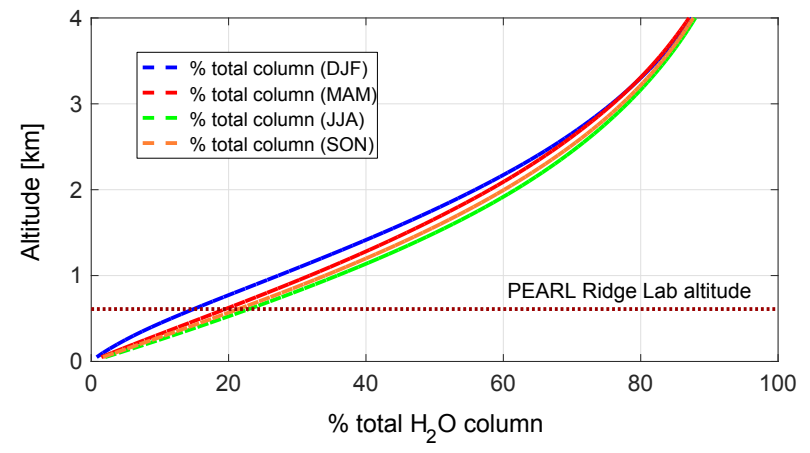

Figure 2. Distribution of water vapour above Eureka from radiosonde profiles (August 2006 to December 2015). The black line illustrates how much of the total column is beneath a given altitude. One fifth of the water vapour total column is typically located beneath $610 \mathrm{~m}$, the altitude of the PEARL Ridge Lab (noted by the dotted dark red line). The horizontal lines show the altitudes at which each quartile is passed. (a) Altitudes up to $15 \mathrm{~km}$. (b) The mean distribution of the water vapour total column up in the lower troposphere by season.

and long fall (September-December). This reflects the physical character of the annual changes at Eureka (Lesins et al., 2010). The water vapour mixing ratio profiles vary by an order of magnitude between winter and summer. The maximum mixing ratio of water vapour in the atmosphere above Eureka is at the surface during summer months. During the rest of the year, water vapour abundances reach their maximum $1-2 \mathrm{~km}$ above the surface.

When analysing the ability of different measurement techniques to capture information about water vapour, its vertical distribution should be considered. Figure 2 illustrates the portion of the total column typically found beneath a given altitude, using EWS radiosonde data from January 2007 to December 2015; $90 \%$ of the Eureka water vapour total column is found beneath an altitude of $4.40 \mathrm{~km}$, while $50 \%$ is found beneath an altitude of $1.60 \mathrm{~km}$. Seasonal analysis gives similar results; however, there are differences in the vertical distribution of water vapour in the lowest few kilometres. The lowest altitudes contain more of the total column during the summer than during the winter. This may be due to the availability of local humidity sources during the summer, when there is open water in the neighbouring fjord. Ground- 
Table 1. Eureka water vapour datasets.

\begin{tabular}{|c|c|c|c|c|c|c|c|c|c|}
\hline \multirow[b]{2}{*}{ Site } & \multirow[b]{2}{*}{ Instrument } & \multirow[b]{2}{*}{ Period } & \multicolumn{3}{|c|}{ Measurement } & \multicolumn{4}{|c|}{$\begin{array}{c}\text { Precipitable water } \\
\text { vapour dataset }(\mathrm{mm})\end{array}$} \\
\hline & & & Duration & Frequency & Number & Mean & $\sigma$ & Min & Max \\
\hline \multirow[t]{4}{*}{$\begin{array}{l}\text { Ridge } \\
\text { Lab } \\
(610 \\
\text { ma.s.1.) }\end{array}$} & $\begin{array}{l}125 \mathrm{HR} \\
\text { MUSICA } \\
\text { extended }\end{array}$ & $\begin{array}{l}\text { Aug 2006- } \\
\text { Oct } 2014\end{array}$ & $5 \min$ & $\begin{array}{l}0-12 \text { day }^{-1} \\
\text { between late } \\
\text { Feb and } \\
\text { mid-Oct }\end{array}$ & $\begin{array}{l}3364 \\
(2713 \text { with } \\
\left.\mathrm{SZA}>85^{\circ}\right)\end{array}$ & 6.9 & 3.5 & 0.9 & 17.9 \\
\hline & $\begin{array}{l}125 \mathrm{HR} \\
\text { MUSICA } \\
\text { standard }\end{array}$ & $\begin{array}{l}\text { Aug 2006- } \\
\text { Aug } 2014\end{array}$ & $5 \mathrm{~min}$ & $\begin{array}{l}1-12 \text { day }^{-1} \\
\text { late Mar to } \\
\text { mid-Sept }\end{array}$ & 1889 & 5.4 & 3.8 & 0.4 & 19.1 \\
\hline & $\begin{array}{l}\text { Sun pho- } \\
\text { tometer }\end{array}$ & $\begin{array}{l}\text { Mar 2007- } \\
\text { Sept } 2015\end{array}$ & $1 \mathrm{~min}$ & $\begin{array}{l}\text { continuously } \\
\text { when sunlight } \\
\text { and clear skies } \\
\text { available }\end{array}$ & 89867 & 6.7 & 3 & 0.6 & 19.2 \\
\hline & E-AERI & $\begin{array}{l}\text { Oct } 2008- \\
\text { Sept } 2009\end{array}$ & $7 \mathrm{~min}$ & continuously & 6596 & 3.5 & 3.3 & 0.7 & 15.5 \\
\hline \multirow[t]{4}{*}{$\begin{array}{l}\text { OPAL } \\
(10 \\
\text { ma.s.1. })\end{array}$} & $\begin{array}{l}\text { Sun pho- } \\
\text { tometer }\end{array}$ & $\begin{array}{l}\text { Apr 2007- } \\
\text { Sept } 2013\end{array}$ & $1 \mathrm{~min}$ & $\begin{array}{l}\text { continuously } \\
\text { when sunlight } \\
\text { and clear skies } \\
\text { available }\end{array}$ & 63010 & 10.3 & 3.5 & 1.7 & 21.1 \\
\hline & $\begin{array}{l}\text { Microwave } \\
\text { radiometer }\end{array}$ & $\begin{array}{l}\text { Aug 2006- } \\
\text { Jun } 2010\end{array}$ & 5 min averages & continuously & 368706 & 5.1 & 4.1 & 0.1 & 26.8 \\
\hline & P-AERI & $\begin{array}{l}\text { Mar 2006- } \\
\text { Apr } 2009\end{array}$ & $1 \mathrm{~min}$ & continuously & 397273 & 4.1 & 3.7 & 0.6 & 25.3 \\
\hline & E-AERI & $\begin{array}{l}\text { Feb 2011- } \\
\text { July } 2013\end{array}$ & $7 \mathrm{~min}$ & continuously & 24395 & 4.3 & 4.4 & 0.6 & 17.7 \\
\hline \multirow{2}{*}{$\begin{array}{l}\text { Eureka } \\
\text { Weather } \\
\text { Station } \\
\text { (10 } \\
\text { m a.s.l.) }\end{array}$} & Radiosonde & $\begin{array}{l}\text { Aug 2006- } \\
\text { Dec } 2015\end{array}$ & $\begin{array}{l}120 \mathrm{~min} \\
(60 \mathrm{~min} \text { tropo- } \\
\text { sphere })\end{array}$ & twice per day & 6852 & 5.5 & 4.6 & 0.4 & 27.1 \\
\hline & $\begin{array}{l}\text { Radiosonde } \\
\text { GRUAN }\end{array}$ & $\begin{array}{l}\text { Sept } \\
2008-M a r \\
2013\end{array}$ & $\begin{array}{l}120 \mathrm{~min} \\
(60 \mathrm{~min} \text { tropo- } \\
\text { sphere) }\end{array}$ & $\begin{array}{l}\text { twice per day, } \\
\text { but with gaps }\end{array}$ & 2374 & 5.3 & 4.8 & 0.4 & 23.6 \\
\hline
\end{tabular}

based and satellite instruments without sensitivity to the lowest altitudes may be seasonally biased and underestimate total columns more in summer than in winter.

Detailed studies of the High Arctic water cycle require more frequent measurements than radiosondes can provide, observations at all altitudes, and precise observations of water vapour isotopes to reveal information about the transport history of water vapour. Measurements taken by PEARL instruments are helping to fill the gap in High Arctic measurements. This study offers a detailed comparison of PEARL water vapour datasets and adds an analysis of a remote Canadian High Arctic site to a collection of other water vapour intercomparison studies done in a subtropical climate (Izaña) by Schneider et al. (2010), an alpine climate (Mt. Zugspitze) by Sussmann et al. (2009), a sub-Arctic climate (Kiruna) by Buehler et al. (2012), and an Arctic climate (Ny Ålesund) by Palm et al. (2010).

\section{Instrumentation near Eureka}

A variety of instruments offer information about water vapour near Eureka. Table 1 summarizes the available datasets and notes how often measurements are taken. Figure 3 illustrates the atmospheric water vapour measurement time series from each PEARL and EWS instrument. The PEARL Ridge Lab hosts the 125HR solar absorption FTIR spectrometer and a sun photometer (SPM). OPAL hosts an- 

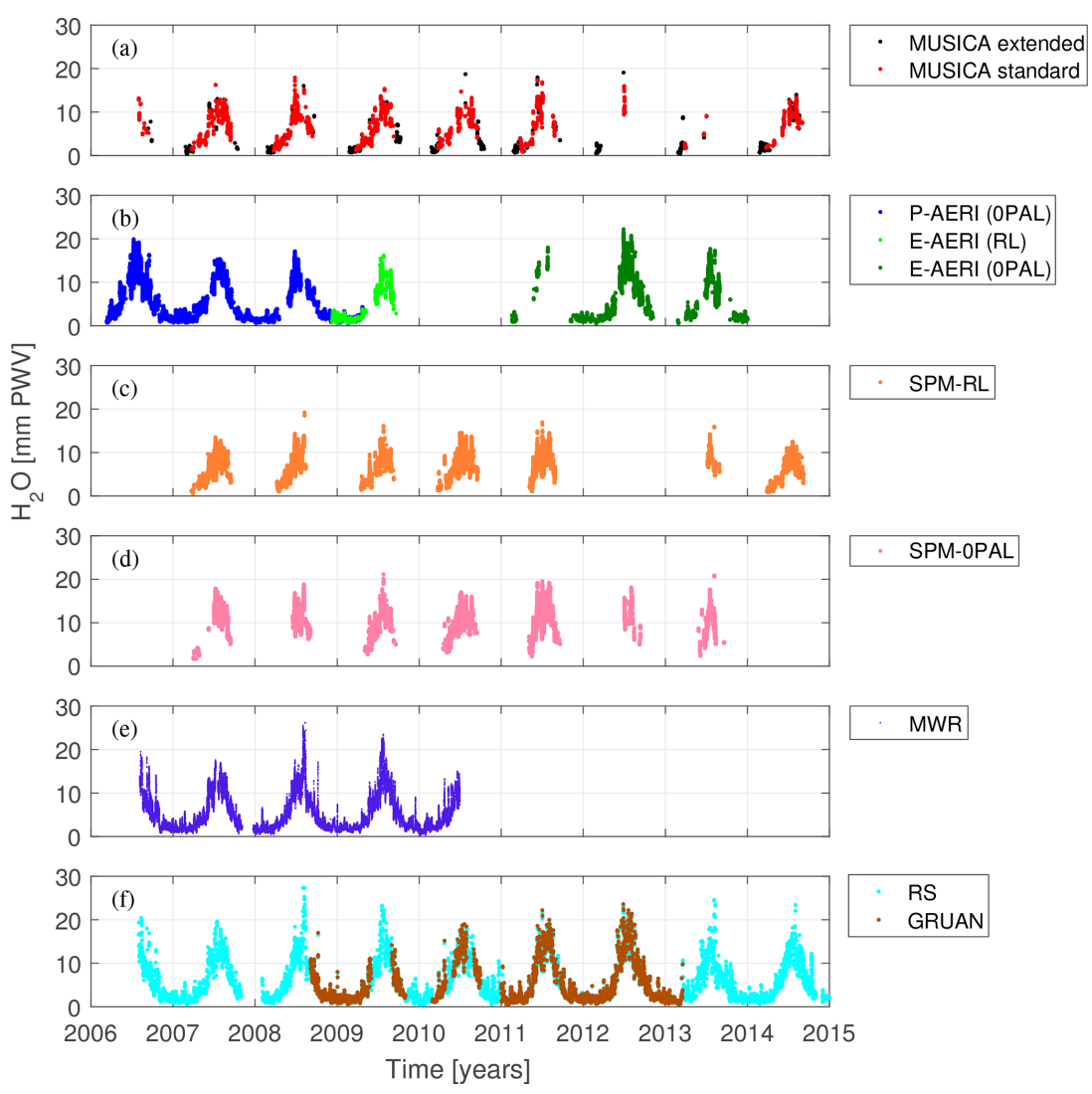

Figure 3. Total column precipitable water vapour (PWV) at Eureka. (a) 125HR water vapour. The extended time series has relaxed the MUSICA SZA quality control criterion of the standard MUSICA time series. (b) P-AERI and E-AERI datasets, with location of the E-AERI noted. (c) the Ridge Lab's SPM dataset. (d) OPAL's SPM dataset. (e) MWR dataset. (f) Eureka Weather Station radiosonde dataset, showing the standard data product as well as the GRUAN product.

other SPM and a microwave radiometer (MWR). During the time period examined in this study, there were also emission FTIR instruments that observe downwelling longwave radiation installed at the Ridge Lab and at OPAL. The EWS launches radiosondes twice per day. All datasets reveal the strong seasonal pattern of maximum total column during the warmer summer and minimum total columns during the winter. This section describes these instruments, their water vapour measurement techniques, and uncertainties.

\subsection{PEARL solar absorption Fourier transform infrared spectrometer}

The Bruker IFS 125HR FTIR spectrometer (125HR) is a solar absorption FTIR instrument located at the PEARL Ridge Lab. It was installed in July 2006 and joined NDACC thereafter (Batchelor et al., 2009). The 125HR records highresolution solar absorption spectra $\left(0.0035 \mathrm{~cm}^{-1}\right)$ during clear-sky conditions while the sun is above the horizon (late February until late October). Its wide spectral range enables the $125 \mathrm{HR}$ to detect many trace gases, including $\mathrm{NO}_{y}$ species (Lindenmaier et al., 2011), stratospheric ozone chemistry species (Lindenmaier et al., 2012), and biomass burning products (Viatte et al., 2015). The $125 \mathrm{HR}$ can also measure atmospheric water vapour and is the most northern measurement site of the NDACC, Total Carbon Column Observing Network (TCCON), and MUSICA networks.

The 125HR water vapour dataset used in this study, illustrated in Fig. 3a, was produced using the MUSICA retrieval technique summarized in Schneider et al. (2016) and Barthlott et al. (2017). This process applies an Optimal Estimation technique based on Rodgers (2000) and uses the PROFITT retrieval code of Hase et al. (2004). By using a combination of strong and weak absorption features and a logarithmic scale, the MUSICA retrieval technique seeks to ensure high accuracy and precision across the highly variable abundances of water vapour.

In addition to total columns, vertical information about water vapour is recovered using the MUSICA retrieval technique. Retrievals from PEARL 125HR measurements typically have 2.9 degrees of freedom for signal, which represent the number of independent pieces of information acquired about the profile. Figure 4 depicts the rows of a typical MUSICA averaging kernel for Eureka, showing the measurement's sensitivity (the sum of the averaging kernel matrix 


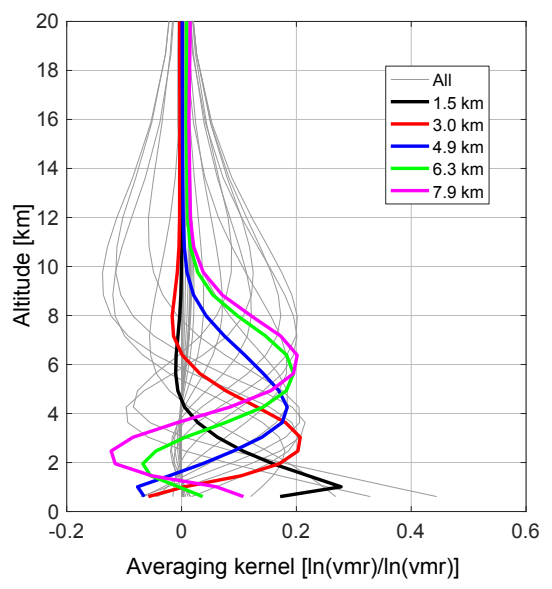

(a)

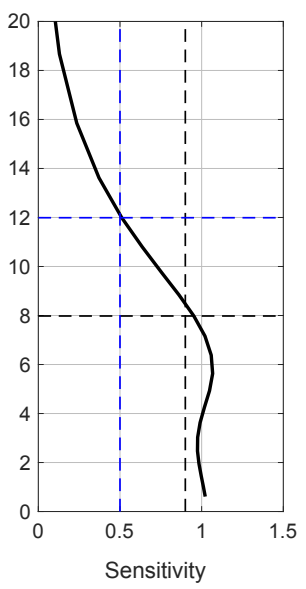

(b)
Figure 4. (a) Example of a typical MUSICA averaging kernel for a Eureka 125HR measurement, taken on 3 August 2006. Five altitudes are highlighted in colour to illustrate the measurement's ability to distinguish between different parts of the troposphere. (b) The retrieval's sensitivity, i.e. the sum of the row kernels, with two thresholds for measurement information noted by dashed lines. The highest altitude where sensitivity is above $0.9(8.0 \mathrm{~km})$ and 0.5 $(12.0 \mathrm{~km})$ is shown using blue and black dashed lines, respectively.

rows) to information originating at different altitudes. Information about water vapour's vertical distribution is mostly limited to the troposphere.

The MUSICA data product also includes total columns of the water vapour isotopologue $\mathrm{HDO}$ and its ratio with $\mathrm{H}_{2} \mathrm{O}$, $\delta \mathrm{D}$, with limited vertical information. This opens up the possibility of investigating the transport history of water vapour (e.g. Schneider et al., 2016) and is a unique contribution to the measurements acquired at PEARL.

\subsubsection{MUSICA quality control}

MUSICA nominally excludes measurements from spectra recorded at SZAs greater than $78.5^{\circ}$. However, this quality control criterion has been relaxed for this study. In addition to filtering out occasional measurements throughout the year, the SZA criterion excludes all measurements obtained between late February (polar sunrise) and late March as well as between mid-September and late October (polar sunset) due to solar-viewing geometries at high latitudes. Figure $3 \mathrm{a}$ shows both the standard MUSICA dataset with the normal SZA filter applied and the extended MUSICA dataset with this criterion removed.

Justification for the $78.5^{\circ} \mathrm{SZA}$ criterion can be seen when examining the SZA dependence of the systematic (e.g. spectroscopic parameters) and statistical errors (e.g. measurement noise). These uncertainty sources are discussed in detail by Schneider et al. (2012). Figure 5a illustrates that the total error increases rapidly close to $90^{\circ}$. Figure 5 b shows that statistical errors begin to increase exponentially for SZAs larger
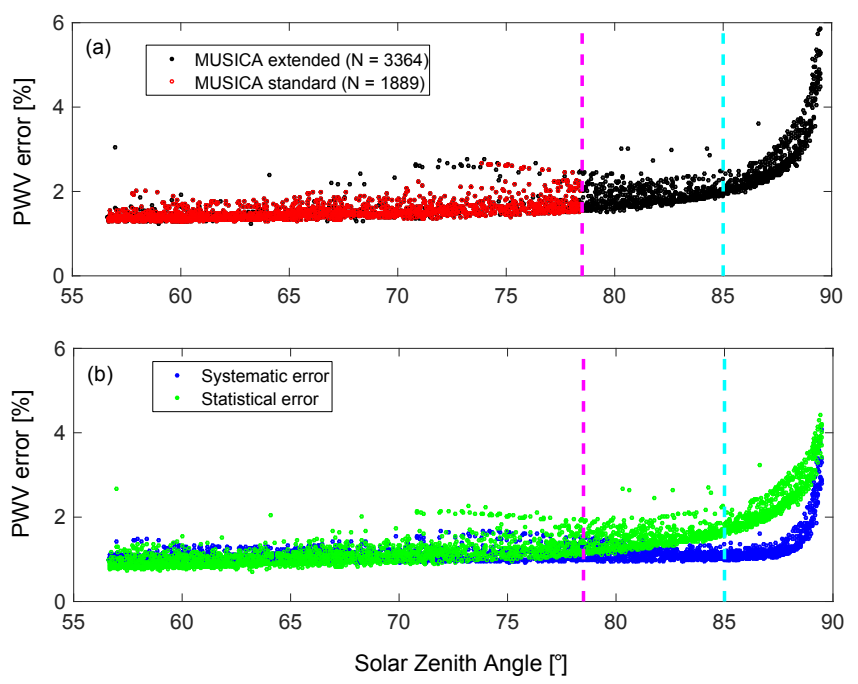

Figure 5. Eureka MUSICA water vapour total error vs. SZA. The dashed magenta line denotes the $78.5^{\circ}$ SZA criterion which is part of the standard MUSICA quality control. The dashed cyan line denotes the $85^{\circ} \mathrm{SZA}$ threshold used in this study for water vapour total column comparisons. (a) The total error. (b) The statistical and systematic errors. The MUSICA extended dataset includes data usually filtered out by MUSICA's quality control criteria.

than $78.5^{\circ}$. For the total column comparisons with other instruments, a SZA limit of $85^{\circ}$ was applied to the $125 \mathrm{HR}$ dataset. Errors increase significantly beyond this point. Including data between 78.5 and $85^{\circ}$ improves the number of measurements available for this study's comparisons. Table 3 shows that different SZA limits have a small impact on observed agreement with other instruments.

The sensitivity of MUSICA retrievals to different altitudes is important to consider when performing profile comparisons. This varies from measurement to measurement and has a seasonal dependency. MUSICA retrievals at Eureka consistently have information throughout the lower and middle troposphere (i.e. sensitivity above 0.9 ) and often in the upper troposphere. Some retrievals have information in the lower stratosphere when the sensitivity criterion is relaxed to 0.5 . The sensitivity of MUSICA retrievals reaches its highest altitudes at Eureka during March due to the high air mass.

The MUSICA data are additionally quality controlled by requiring reasonable $\mathrm{XCO}_{2}$ values $\left(\mathrm{CO}_{2}\right.$ column-averaged dry air mole fraction) retrieved from the same spectra that are used for the MUSICA water vapour isotopologue retrievals (for details, see Barthlott et al., 2015). Further quality tests are made by fitting solar line shifts and phase errors of the instrumental line shape (for a summary, see Barthlott et al., 2017).

\subsection{Emission FTIR instruments}

Two related FTIR instruments that observe atmospheric emission at PEARL offer water vapour datasets: the 
Extended-range Atmospheric Emitted Radiance Interferometer (E-AERI) and the Polar-Atmospheric Emitted Radiance Interferometer (P-AERI). The AERI instruments built by the ABB Inc. (Knuteson et al., 2004a, b) measure the downwelling radiation emitted by the atmosphere directly above Eureka continuously, weather permitting, at $1.0 \mathrm{~cm}^{-1}$ resolution. E-AERI measurements were calibrated using the standard processing software provided by ABB Inc., while the PAERI measurements included additional processing (Rowe et al., 2011). The spectral range of the E-AERI is 400 to $3000 \mathrm{~cm}^{-1}$ and that of the P-AERI is 500 to $3000 \mathrm{~cm}^{-1}$. EAERI measurements were sampled every $\sim 7 \mathrm{~min}$. P-AERI measurements were sampled every 0.6 to $2 \mathrm{~min}$. Instrument noise in the P-AERI was reduced via a method that employs principal component analysis followed by noise filtering. This method is described in detail by Antonelli et al. (2004) and Turner et al. (2006), and thus we only mention specifics related to the P-AERI here. There are $\sim 3000$ spectral elements (e.g. for $\sim 400$ to $1900 \mathrm{~cm}^{-1}$ at $0.5 \mathrm{~cm}^{-1}$ spacing). To ensure that the number of samples, or downwelling radiance spectra, is sufficiently greater than the number of spectral elements, we process 10000 samples at a time. The number of principal components retained is determined according to Turner et al. (2006) and is typically between 85 and 240 .

The sensitivity of downwelling infrared radiance to water vapour is greatest at low altitudes, where water vapour is most abundant. While AERI measurements have been used to retrieve water vapour profiles (e.g. Feltz et al., 2003), retrievals of water vapour using AERI measurements in this work are limited to total column amounts. Measurements of trace gases and radiances taken by these two AERI instruments have been shown to be consistent with each other (Mariani et al., 2012, 2013).

The radiosonde profiles are used as an input to the AERI retrieval. The shape of the water vapour profile is determined by the radiosondes. However, the AERI instruments are used to retrieve water vapour in between the twice-daily radiosondes, assuming the shape of the water vapour profile changes linearly. The resulting AERI water vapour retrievals have a much finer temporal resolution. Furthermore, water vapour retrievals have been performed only during time periods identified as being clear sky, following a cloud-screening procedure detailed in the Appendix.

The P-AERI was installed at OPAL in March 2006. The E-AERI was installed at the PEARL Ridge Lab in October 2008 (Mariani et al., 2012). After a 7-month overlap period with the E-AERI, the P-AERI was removed. Due to damage incurred to its detectors, the E-AERI did not take measurements between September 2009 and February 2011. Once repaired, the E-AERI was moved to OPAL, where it remains.

This study will refer to the combined dataset as the AERI; however, its three components will be examined: the P-AERI dataset at OPAL, the E-AERI dataset at OPAL, and at the EAERI dataset while installed at the Ridge Lab. Distinguish- ing between the two measurement locations is important because of the difference in elevation and because water vapour is most abundant at low altitudes. These datasets are illustrated in Fig. 3b.

The PEARL AERI water vapour products are new and published here for the first time. The retrieval technique applied to the AERI measurements to produce the water vapour dataset is based on Rowe et al. (2008). This technique, as well as modifications made for this work, is described in the Appendix. Uncertainties in retrieved precipitable water vapour (PWV) are 3 to $11 \%$ for summer to winter cases.

\subsection{Sun photometer}

The PEARL Ridge Lab and OPAL have both hosted a Cimel SPM. These datasets are illustrated in Fig. 3c and d, which show higher total columns measured at OPAL due to the lower altitude (see Fig. 2). SPMs measure solar radiation in eight spectral channels between 340 and $1640 \mathrm{~nm}$. These automated sun-viewing radiometers are part of the global Aerosol Robotic Network (AERONET) and contribute data to a global aerosol optical depth database (Holben et al., 1998). In this report, the AERONET Level 2.0 data product is used, which has been cloud-screened and quality assured according to Smirnov et al. (2000). The Eureka SPMs are calibrated annually and reinstalled in the spring.

SPM data are used to produce total column aerosol optical depth measurements from inversions of spectral directsun and sky radiances. For water vapour measurements, a modified Langley plot technique described by Holben et al. (1998) is applied to observations of a spectral window at $940 \mathrm{~nm}$. The AERONET water vapour retrieval is described by Smirnov et al. (2004). SPMs make measurements approximately every $3 \mathrm{~min}$ but are limited to clear-sky conditions. The Ridge Lab and OPAL AERONET water vapour datasets do not have measurement uncertainties in the posted data files. Validation studies of the AERONET Cimel SPMs have shown that their data underestimates the water vapour total column by $10 \%$ (Alexandrov et al., 2009) and $5 \%$ (PérezRamírez, 2014).

\subsection{Microwave radiometer}

The MWR at OPAL, a Radiometrics WVQ-1500, was installed in March 2006 in collaboration with NOAA. The MWR records microwave emissions in five channels between 22 and $30 \mathrm{GHz}$ with a beam width of $5^{\circ}$. Two of the channels are used to statistically derive the PWV from zenith-pointing measurements (see Liljegren and Lesht, 1996; Westwater et al., 2001). The measurements and retrieval technique are applied a few times per minute. This technique enables the MWR to observe water vapour all day and night in most conditions (e.g. during non-precipitating clouds) and to capture short-term variability. For use in this study, $5 \mathrm{~min}$ averages have been calculated. This MWR time series is shown 
in Fig. 3e. The MWR dataset has been limited to the time period before mid-2010 due to possible calibration problems thereafter. There has not been maintenance and calibration of the MWR, on account of its remote location, since a 2008 visit.

\subsection{Radiosondes}

Radiosondes are widely used to measure temperature, pressure, and atmospheric water vapour (e.g. relative humidity, dew point temperature) at meteorological stations around the world. Eureka radiosonde measurements are taken by an instrument payload lofted into the atmosphere by a hydrogenfilled balloon, launched twice daily (11:15 and 23:15 UT) from the EWS. Occasionally, radiosondes are launched at other times of the day for campaign-related reasons. Typically, these balloons (and the measurements) reach the middle of the stratosphere ( 30 to $33 \mathrm{~km}$ ). In this work, if a radiosonde did not reach $15 \mathrm{~km}$, its data were filtered out. This ensures the calculation of the total column using an integrated profile is justifiable. Indeed, the available GRUAN-processed radiosonde measurements reveal that $99.6 \%(\sigma=0.6 \%)$ of the water vapour column above Eureka is located below $15 \mathrm{~km}$.

The Vaisala RS-92 radiosonde model currently used by the EWS has been subject to extensive testing and validation. Relative humidity is measured using a thin-film capacitor. This design has been shown to work well at cold temperatures (below $-70^{\circ} \mathrm{C}$ ) and low abundances (below 5 ppmv), but its sensitivity to water vapour is limited at low pressures (Miloshevich et al., 2009). Moreover, the reported relative humidity values are given in whole numbers, whereas the measured values include two decimal place precision (Miloshevich et al., 2009). The RS-92 Vaisala radiosonde model is also known to have a dry radiation bias due to solar heating of the sensor (Vömel et al., 2007). Measurements taken during the AIRS Water Vapour Experiment (AWEX) campaign at the Atmospheric Radiation Measurement Southern Great Plains site in 2004 showed a daytime dry bias of 6-8\% when compared to a co-located microwave radiometer (Miloshevich et al., 2009). This error depends on the solar radiation intensity, which is a function of the SZA and sensor orientation. The lack of a protective cover introduces a second error source, which partially offsets the radiative heating: forced cooling occurs as the sensor rises with the balloon. This effect depends strongly on pressure and thus decreases with altitude.

Radiosonde relative humidity measurements were converted to mixing ratio using the radiosonde pressure measurements and the equation for saturation vapour pressure over liquid water from Wexler (1976). Use of this equation aligns with Vaisala's instrument calibration. The $\mathrm{H}_{2} \mathrm{O}$ mixing ratio profile was then converted to a number density profile using the temperature and pressure radiosonde profiles (i.e. using the ideal gas law to calculate a number density of air
Table 2. Estimated accuracies of water vapour column retrievals for Eureka instruments.

\begin{tabular}{|c|c|c|}
\hline Instrument & Accuracy & Reference \\
\hline $\begin{array}{l}\text { 125HR (MUSICA } \\
\text { extended) }\end{array}$ & $\begin{array}{l}1.80 \% \\
(\sigma=0.61 \%)\end{array}$ & $\begin{array}{l}\text { Calculated from the combined } \\
\text { uncertainties of each datapoint }\end{array}$ \\
\hline $\begin{array}{l}\text { 125HR (MUSICA } \\
\text { standard) }\end{array}$ & $\sim 1 \%$ & Schneider et al. (2012) \\
\hline Sun photometer & $5-10 \%$ & $\begin{array}{l}\text { Pérez-Ramírez (2014) and } \\
\text { Alexandrov et al. (2009) }\end{array}$ \\
\hline $\begin{array}{l}\text { Microwave } \\
\text { radiometer }\end{array}$ & $\sim 20 \%$ & Westwater et al. (2001) \\
\hline Radiosonde & $\sim 15 \%$ & Miloshevich et al. (2009) \\
\hline GRUAN & $\begin{array}{l}5.70 \% \\
(\sigma=1.6 \%)\end{array}$ & Calculated \\
\hline E-AERI & $3-11 \%$ varies monthly & Rowe et al. (2008) \\
\hline P-AERI & $3-11 \%$ varies monthly & Rowe et al. (2008) \\
\hline
\end{tabular}

profile). The $\mathrm{H}_{2} \mathrm{O}$ number density profile was then integrated and converted to mm of PWV for total column comparisons.

In addition to providing a total column measurement, the high vertical resolution of the radiosonde measurements permits the calculation of partial columns above and below the Ridge Lab altitude (following the same procedure described for the total column calculation). The profile above $610 \mathrm{~m}$ has been compared with Ridge Lab instruments to ensure the results are fair despite the altitude difference between the Ridge $\mathrm{Lab}$ and the radiosonde launch point. The radiosonde profile below $610 \mathrm{~m}$ has been used to examine the partial column between the two measurement sites. Radiosonde measurements show the PWV of the partial column between the measurement sites remains below $5 \mathrm{~mm}$; between January and March this partial column reaches values beneath $0.1 \mathrm{~mm}$.

\subsubsection{GRUAN}

Eureka is not a GRUAN site; however, a subset of the Eureka radiosonde data has been processed using the GRUAN technique for this study. The GRUAN analysis requires the raw radiosonde files. There are gaps in Eureka's raw file record, which results in a smaller number of GRUAN measurements than the standard radiosonde product. GRUAN aims to provide a traceable reference standard (Immler et al., 2010), motivating its inclusion in this study. GRUAN data processing for the RS-92 instrument is described by Dirksen et al. (2014) and accounts for known biases in radiosonde measurements. PWV partial columns above and below the Ridge Lab altitude have been calculated and used in the same manner as described for the radiosonde measurements. This study is the first time Eureka radiosonde measurements processed using the GRUAN technique have been produced and presented.

Another advantage of the GRUAN processing is that it recovers GPS location information about radiosonde flights, enabling an estimation of typical flight paths and distances from Eureka. The input for this reanalysis of the radiosonde measurements required raw data files, which were not available for all sonde flights. This is illustrated in Fig. 3f, which 


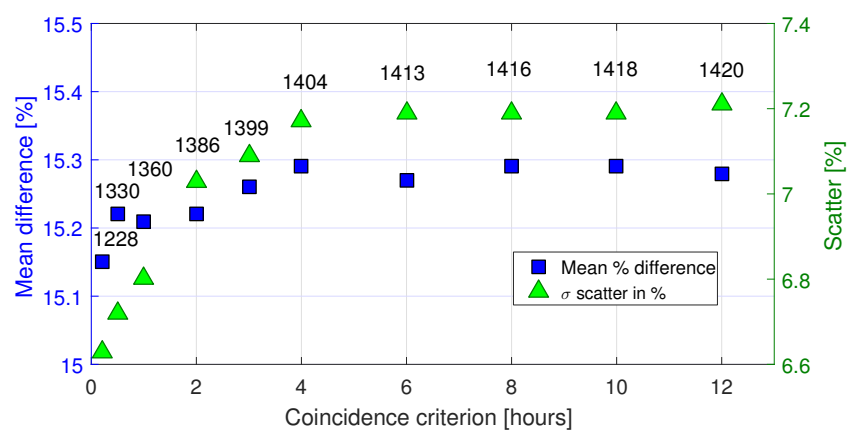

Figure 6. The variation in mean percent difference and scatter (1 standard deviation) between the water vapour total column of the $125 \mathrm{HR}$ and SPM at the Ridge Lab comparison as a function of the temporal coincidence criterion. The resulting number of coincidences at each temporal coincidence criterion is labelled next to each data pair.

shows both the radiosonde and GRUAN time series. Based on the available raw radiosonde files processed by GRUAN, radiosondes launched from the EWS typically stay close to Eureka. Radiosondes reached a mean maximum (horizontal) distance from the Eureka launch point of $62.6 \mathrm{~km}$ $(\sigma=48.0 \mathrm{~km})$ and $82.5 \%$ of flights stayed within $100 \mathrm{~km}$ of the Ridge Lab. Moreover, radiosondes had a mean maximum distance of $20.1 \mathrm{~km}(\sigma=11.3 \mathrm{~km})$ in the lowest $10 \mathrm{~km}$ of the atmosphere (GRUAN measurements show $99.4 \%$ of the water column is beneath this altitude, on average). These results demonstrate that the radiosonde measurements, despite the balloon's ability to drift away from the EWS with the wind, are representative of the atmosphere above Eureka.

\subsection{Summary of Eureka water vapour datasets}

This section has presented the water vapour datasets from several ground-based PEARL instruments and Eureka radiosondes. The altitude of an instrument has a significant impact on the water vapour total columns observed; therefore, analysis of the datasets distinguishes between the instruments located at the OPAL and Ridge Lab sites. Table 1 summarized these datasets and notes how often measurements are taken, at which location and altitude the instrument is located. Information about each dataset's mean, standard deviation $(\sigma)$, and minimum and maximum recorded PWV values are included. These dataset characteristics are influenced by sampling limitations, particularly in the case of instruments dependent on sunlight. Nonetheless, the datasets presented in this study indicate the Eureka total column of water vapour can vary substantially, with values as small as $0.4 \mathrm{~mm}$ PWV and as large as $27 \mathrm{~mm}$ PWV recorded by the radiosondes. Indeed, Fig. 3 shows that water vapour columns at Eureka rarely exceed $20 \mathrm{~mm}$ PWV during summer and columns are frequently below $2 \mathrm{~mm}$ PWV during winter. In contrast, near the Equator, where PWV values can be as large as $50 \mathrm{~mm}$. Table 2 summarizes estimated accuracies for the water vapour products, based on information available for each.

\section{Comparison of water vapour measurements}

In this study, water vapour total columns are compared using PWV units. This unit represents the height of the layer of water that would result from the condensation of the entire total column to standard temperature and pressure. (It may be useful to note that $\mathrm{mm} \mathrm{PWV}$ is equivalent to $\mathrm{kg} \mathrm{m}^{-2}$.)

\subsection{Method}

Coincident total column measurements have been compared using difference and correlation plots. No instrument is used as a common reference. A full accounting of the differences between every combination of instruments is presented to show how each dataset relates to the others.

When comparing with the $125 \mathrm{HR}$, radiosonde profiles were smoothed by the 125HR averaging kernel and then integrated to calculate the total column. The procedure for smoothing followed Rodgers and Connor (2003). This accounts for altitude sensitivity differences between the instruments. Before smoothing, the $125 \mathrm{HR}$ a priori profile is used to fill any gaps in the comparison profile (i.e. altitudes above the upper limit of radiosonde measurements). After smoothing, altitudes for which there were no original data were removed.

In this study, measurements are compared using absolute and percent differences. These are calculated using

$$
\begin{aligned}
\text { difference } & =X-Y, \\
\% \text { difference } & =\frac{(X-Y)}{\frac{X+Y}{2}} \times 100 \% .
\end{aligned}
$$

Percent differences are considered with respect to the average of the two measurements to avoid taking one of them as a reference.

When reporting the comparison results in the text, the standard error in the mean (SEM) is used to quantify the expected accuracy of the mean difference; i.e. a difference will be quoted as $A \pm B$, where $A$ is the mean difference $(\Delta)$ and $B$ is the SEM. The figures showing differences use the mean difference as well as the 1 standard deviation of the differences to characterize the spread of the values $(\sigma)$. The tables summarizing the results also include the root-mean-square differences (RMSD). Results reported also includes the total number of matches found between the comparison instruments $(N)$.

\subsection{Coincidence criteria}

A $2 \mathrm{~h}$ temporal coincidence criterion was applied for all instrument comparisons. If multiple coincident measurements 


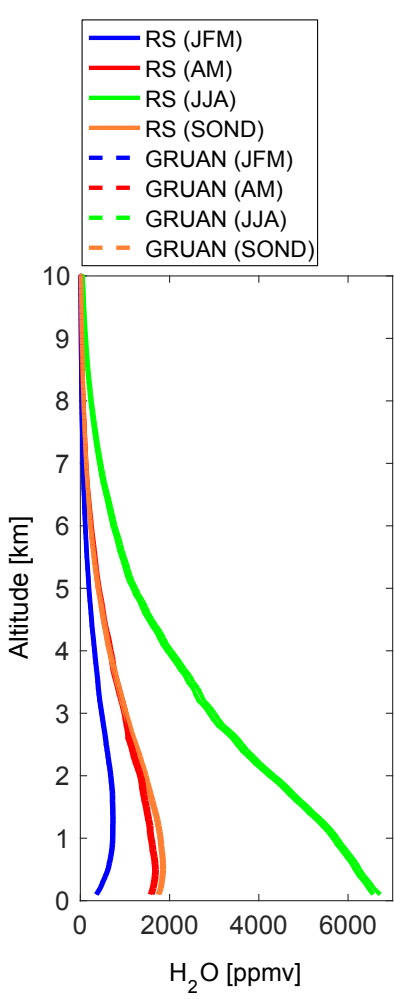

(a)

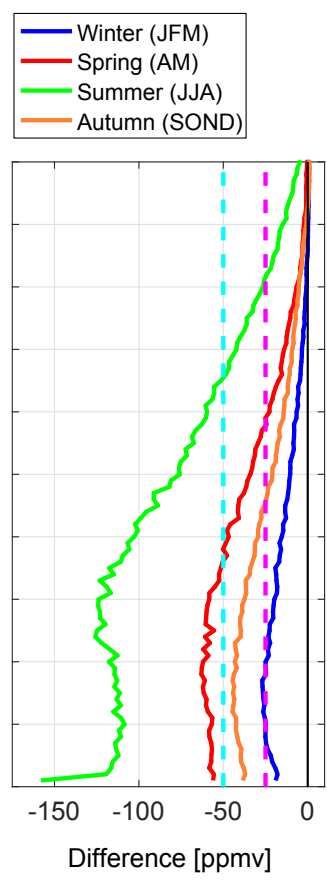

(b)

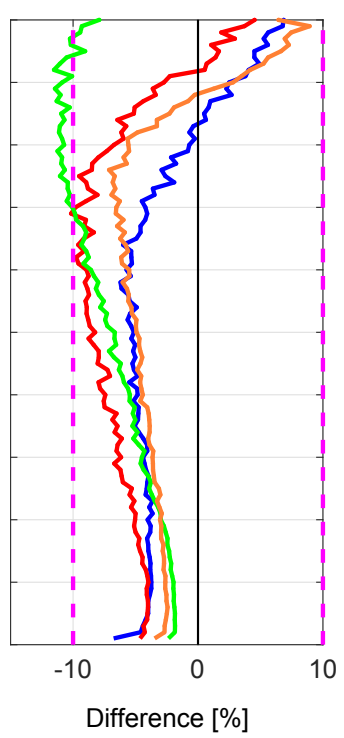

(c)

Figure 7. (a) Coincident radiosonde (RS) and GRUAN profiles by season. (b) Differences between the profiles. (c) Percent differences. ( $X$ is RS and $Y$ is GRUAN in Eqs. 1 and 2.)

were found within this interval, only the closest pair was kept. Each matched pair is thus independent of others contributing to the overall assessment of different measurement techniques. This method often results in a substantially smaller time difference between measurements than is otherwise permitted by the criterion. For example, the mean time difference between measurements used in the comparison between the $125 \mathrm{HR}$ and sun photometer was $5.4 \mathrm{~min}$. All comparisons were also performed using all possible pairs of coincidences within this criterion (not shown). While significantly increasing the number of matches, the observed agreement between instruments was very similar.

The wide time criterion was chosen to ensure sufficient matches were found for a reasonable study, especially for comparisons involving the radiosondes. Radiosondes are launched twice a day at 06:15 and 18:15 local time. This generally does not align with measurements that require sunlight (i.e. SPMs, 125HR), especially during spring and fall. Figure 6 illustrates the trade-off between the mean percent difference (and scatter, the mean standard deviation) between the 125HR and radiosonde and SPM measurements. The scatter shows how consistently different the instruments are at each temporal coincidence criterion.

Other instruments show similar patterns with an initial increase in the number of coincident pairs levelling off for a larger temporal coincidence criterion. Since only the closest pair is kept, the benefit to a larger temporal criterion is much less when the comparison instrument offers a high temporal density of data (e.g. the 125HR and RL SPM). The mean time difference of coincident measurements was less than $10 \mathrm{~min}$ in all cases except those involving the radiosonde datasets. The majority of coincident measurements involving the radiosonde datasets are within $30 \mathrm{~min}$, except the $125 \mathrm{HR}$ vs. radiosonde comparison (where the mean time difference was $55.0 \mathrm{~min}$ and $43 \%$ of coincident measurement pairs were within $30 \mathrm{~min}$ ).

\subsection{Radiosondes}

The accuracy of the Eureka radiosonde dataset is usefully characterized by comparison to the 2371 radiosonde measurements processed by GRUAN. The radiosonde and GRUAN total columns agree closely, with a mean difference (RS-GRUAN) of $-3.7 \pm 0.0 \%(R=1.00)$. Differences reveal that the Eureka radiosonde water vapour total columns have a small systematic difference relative to GRUAN. The magnitude of this underestimation of water vapour varies seasonally, with radiosonde columns dry biased by up to around $1 \mathrm{~mm}$ PWV during the summer $(0.6 \mathrm{~mm}$ PWV or $5.0 \%$ on average). During winter, agreement is very close; 
the differences in the columns are $0.1 \mathrm{~mm}$ PWV (or $4.2 \%$ ) on average. This is seen clearly in the profile differences, as shown in Fig. 7.

\section{$3.4 \quad 125 \mathrm{HR}$}

The PEARL Ridge Lab's 125HR water vapour measurements show good agreement with those of other Ridge Lab instruments. The percent differences between the 125HR and instruments located at the Ridge Lab or with sufficient profile information to create a total column from the altitude of the Ridge Lab $(610 \mathrm{~m})$ are illustrated by Fig. 8 .

The Ridge Lab SPM shares the same location and the same solar-viewing measurement geometry as the $125 \mathrm{HR}$. Despite measuring the same air mass at the same time (the mean difference in measurement time between the $125 \mathrm{HR}$ and RL SPM is $5.4 \mathrm{~min}$ ), Fig. 8a shows that RL SPM measurements are consistently smaller than the $125 \mathrm{HR}$. The MUSICA product is consistently wet biased (measures more water vapour) with respect to the SPM. The difference between the instruments varies seasonally and is largest in the summer. Seasonal variations in the difference between the FTIR spectrometer and sun photometer/radiometers have also been reported by Schneider et al. (2010) for a subtropical site.

During the period of time when the E-AERI was installed at the Ridge Lab, its measurements compared favourably with the 125HR. This is shown in Fig. 8b. The mean percent difference (E-AERI-125HR) in coincident measurements was $-0.4 \pm 0.0 \mathrm{~mm}$ PWV $(-6.5 \pm 0.3 \%)$. This is the closest agreement of all comparisons with the 125HR in this study. It is consistent with the result of the GRUAN comparison, with both showing a similarly sized small overestimation in the Eureka MUSICA product.

When comparing the $125 \mathrm{HR}$ and radiosondes, radiosonde profiles were smoothed with the 125HR averaging kernels and the total column calculated down to the PEARL Ridge Lab altitude of $610 \mathrm{~m}$. Only 65 coincidences were found. As shown in Fig. 8c, the mean difference (125HR - RS) is $0.78 \pm 0.1 \mathrm{~mm}(12.2 \pm 1.1 \%)$, with no clear seasonality. This difference is larger than the expected accuracy of the measurements. The MUSICA product overestimates the water vapour column with respect to the radiosondes, beyond the small dry bias of the radiosondes.

Comparisons with the GRUAN radiosonde products are limited to only 10 coincident measurements. The mean percent difference, shown in Fig. 8d, was $0.4 \pm 0.2 \mathrm{~mm}$ $(-5.2 \pm 3.4 \%)$. Extending the coincidence criterion to allow for measurements within $3 \mathrm{~h}$ instead of $2 \mathrm{~h}$ produces 93 coincidences. In this case, the difference (125HR - GRUAN) is $0.3 \pm 0.0 \mathrm{~mm}(9.0 \pm 1.1 \%)$. (If the radiosonde comparison's criterion was also extended to $3 \mathrm{~h}$, the agreement (125HR RS) would become $0.6 \pm 0.0 \mathrm{~mm}(12.8 \pm 0.0 \%)$ using 279 matches, which is consistent with the $2 \mathrm{~h}$ coincidence criterion result.) This comparison shows that the MUSICA prod- uct (v2015) is likely wet biased, given the differences relative to the GRUAN and radiosonde product.

Table 3 shows that these comparisons (shown in Fig. 8), made with the extended MUSICA dataset with a relaxed $85^{\circ}$ SZA limit applied, are consistent with the agreement that would be found with other Eureka instruments if the standard MUSICA dataset was used.

\subsection{AERI}

Comparisons between the E-AERI while it was located at OPAL and other OPAL instruments show close agreement, as illustrated by Fig. 9. Since AERI measurements occur throughout the day and night, and during polar night, many coincidences are found with radiosondes and the MWR. Comparisons with the E-AERI showed agreement of $3.2 \pm 0.2 \%(N=475)$ with radiosondes, $1.0 \pm 0.3 \%$ $(N=300)$ with GRUAN, and $3.3 \pm 0.1 \%(N=1685)$ with the OPAL SPM (where E-AERI is used as $X$ in Eq. 2). Because MWR measurements were limited to the time period before 1 July 2010, before the E-AERI was installed at OPAL, there were no coincidences between the E-AERI and MWR.

The P-AERI ( $X$ in Eq. 2) showed agreement of $1.7 \pm 0.2 \%(N=639)$ with the radiosondes, $0.5 \pm 0.4 \%$ $(N=108)$ with GRUAN, $2.2 \pm 0.0 \%(N=2662)$ with the OPAL SPM, and $-1.5 \pm 0.1 \%(N=46,054)$ with the MWR.

Comparisons between the E-AERI while it was installed at the PEARL Ridge Lab and Ridge Lab instruments show similar agreement. Observed agreement (where E-AERI is $X$ in Eq. 2) was $-6.5 \pm 0.3 \%(N=191)$ with the $125 \mathrm{HR}$ and $5.6 \pm 0.2 \%(N=898)$. This is illustrated in Fig. 10.

\subsection{OPAL to Ridge Lab partial column comparisons}

As shown in Fig. 2, approximately $20 \%$ of the Eureka water vapour column is found in the $600 \mathrm{~m}$ altitude range between OPAL and the Ridge Lab. Measurements of this partial column have been calculated using the radiosonde and GRUAN profiles. In addition, 37476 near-simultaneous SPM measurements at both sites were used to calculate a partial column, i.e. by subtracting the RL column measurement from the OPAL total column.

Results show the radiosonde and GRUAN partial columns below the Ridge Lab altitude compare very similarly to their total columns (i.e. a mean difference of 3.9 and $3.7 \%$, respectively, where $X=$ GRUAN and $Y=\mathrm{RS}$ in Eq. 2). However, agreement between the partial column calculated from the SPM measurements and those from the radiosonde datasets is relatively poor. The mean difference between the SPM and RS partial columns was $13.7 \pm 1.1 \%(\sigma=25.3 \%)$; the mean difference between the SPM and GRUAN partial columns was $20.7 \pm 1.6 \%(\sigma=22.5 \%)$. 
Table 3. Summary of total column comparison of 125HR with different SZA limits ( $X$ in Eqs. 1 and 2) with co-located Eureka instruments $(Y$ in Eqs. 1 and 2). Reported values include number of coincidences $(N)$, correlation coefficient $(R)$, slope of correlation best fit line $(m)$, mean difference $(\Delta)$, standard deviation of difference $(\sigma)$, standard error of the mean (SEM), and root-mean-square difference (RMSD) in $\mathrm{mm}$ and \%. GRUAN and RS values are partial columns (pc) integrated from the RL altitude and above.

\begin{tabular}{|c|c|c|c|}
\hline & \multicolumn{3}{|c|}{ 125HR MUSICA } \\
\hline & (78.5 SZA limit) & (85 SZA limit) & (no SZA limit) \\
\hline GRUAN (EWS, RL pc) & $\begin{array}{l}N=6 \\
R=0.97 \\
m=0.92 \\
\Delta=0.69 \mathrm{~mm} \\
\sigma=0.66 \mathrm{~mm} \\
\mathrm{SEM}=0.27 \mathrm{~mm} \\
\mathrm{RMSD}=0.92 \mathrm{~mm} \\
\mathrm{PD}=9.77 \% \\
\sigma=7.11 \% \\
\mathrm{SEM}=2.90 \% \\
\text { RMSD }=11.73 \%\end{array}$ & $\begin{array}{l}N=10 \\
R=0.99 \\
m=0.89 \\
\Delta=0.44 \mathrm{~mm} \\
\sigma=0.61 \mathrm{~mm} \\
\mathrm{SEM}=0.19 \mathrm{~mm} \\
\mathrm{RMSD}=0.72 \mathrm{~mm} \\
\mathrm{PD}=5.15 \% \\
\sigma=10.69 \% \\
\mathrm{SEM}=3.38 \% \\
\text { RMSD }=11.38 \%\end{array}$ & $\begin{array}{l}N=19 \\
R=0.99 \\
m=0.88 \\
\Delta=0.16 \mathrm{~mm} \\
\sigma=0.54 \mathrm{~mm} \\
\mathrm{SEM}=0.12 \mathrm{~mm} \\
\mathrm{RMSD}=0.55 \mathrm{~mm} \\
\mathrm{PD}=-1.74 \% \\
\sigma=14.27 \% \\
\mathrm{SEM}=3.27 \% \\
\mathrm{RMSD}=14.00 \%\end{array}$ \\
\hline RS (EWS, RL pc) & $\begin{array}{l}N=55 \\
R=0.96 \\
m=0.90 \\
\Delta=0.88 \mathrm{~mm} \\
\sigma=0.74 \mathrm{~mm} \\
\text { SEM }=0.10 \mathrm{~mm} \\
\text { RMSD }=1.15 \mathrm{~mm} \\
\text { PD }=12.65 \% \\
\sigma=8.52 \% \\
\text { SEM }=1.15 \% \\
\text { RMSD }=15.21 \%\end{array}$ & $\begin{array}{l}N=65 \\
R=0.98 \\
m=0.89 \\
\Delta=0.78 \mathrm{~mm} \\
\sigma=0.73 \mathrm{~mm} \\
\text { SEM }=0.09 \mathrm{~mm} \\
\text { RMSD }=1.06 \mathrm{~mm} \\
\mathrm{PD}=12.19 \% \\
\sigma=8.90 \% \\
\text { SEM }=1.10 \% \\
\text { RMSD }=15.05 \%\end{array}$ & $\begin{array}{l}N=85 \\
R=0.98 \\
m=0.88 \\
\Delta=0.58 \mathrm{~mm} \\
\sigma=0.74 \mathrm{~mm} \\
\mathrm{SEM}=0.08 \mathrm{~mm} \\
\mathrm{RMSD}=0.93 \mathrm{~mm} \\
\mathrm{PD}=8.44 \% \\
\sigma=12.19 \% \\
\mathrm{SEM}=1.32 \% \\
\text { RMSD }=14.77 \%\end{array}$ \\
\hline E-AERI (RL) & $\begin{array}{l}N=168 \\
R=0.99 \\
m=0.93 \\
\Delta=0.51 \mathrm{~mm} \\
\sigma=0.42 \mathrm{~mm} \\
\mathrm{SEM}=0.03 \mathrm{~mm} \\
\mathrm{RMSD}=0.66 \mathrm{~mm} \\
\mathrm{PD}=6.85 \% \\
\sigma=4.30 \% \\
\mathrm{SEM}=0.33 \% \\
\mathrm{RMSD}=8.08 \%\end{array}$ & $\begin{array}{l}N=191 \\
R=1.00 \\
m=0.93 \\
\Delta=0.46 \mathrm{~mm} \\
\sigma=0.42 \mathrm{~mm} \\
\mathrm{SEM}=0.03 \mathrm{~mm} \\
\mathrm{RMSD}=0.62 \mathrm{~mm} \\
\mathrm{PD}=6.49 \% \\
\sigma=4.29 \% \\
\mathrm{SEM}=0.31 \% \\
\mathrm{RMSD}=7.78 \%\end{array}$ & $\begin{array}{l}N=210 \\
R=1.00 \\
m=0.93 \\
\Delta=0.41 \mathrm{~mm} \\
\sigma=0.43 \mathrm{~mm} \\
\text { SEM }=0.03 \mathrm{~mm} \\
\text { RMSD }=0.59 \mathrm{~mm} \\
\mathrm{PD}=5.15 \% \\
\sigma=6.39 \% \\
\text { SEM }=0.44 \% \\
\text { RMSD }=8.20 \%\end{array}$ \\
\hline RL SPM & $\begin{array}{l}N=1280 \\
R=0.99 \\
m=0.84 \\
\Delta=1.05 \mathrm{~mm} \\
\sigma=0.65 \mathrm{~mm} \\
\mathrm{SEM}=0.02 \mathrm{~mm} \\
\mathrm{RMSD}=1.23 \mathrm{~mm} \\
\mathrm{PD}=15.08 \% \\
\sigma=6.50 \% \\
\mathrm{SEM}=0.18 \% \\
\text { RMSD }=16.42 \%\end{array}$ & $\begin{array}{l}N=1304 \\
R=0.99 \\
m=0.84 \\
\Delta=1.04 \mathrm{~mm} \\
\sigma=0.65 \mathrm{~mm} \\
\text { SEM }=0.02 \mathrm{~mm} \\
\text { RMSD }=1.23 \mathrm{~mm} \\
\mathrm{PD}=15.10 \% \\
\sigma=6.48 \% \\
\text { SEM }=0.18 \% \\
\text { RMSD }=16.43 \%\end{array}$ & $\begin{array}{l}N=1386 \\
R=0.99 \\
m=0.83 \\
\Delta=1.06 \mathrm{~mm} \\
\sigma=0.71 \mathrm{~mm} \\
\mathrm{SEM}=0.02 \mathrm{~mm} \\
\mathrm{RMSD}=1.28 \mathrm{~mm} \\
\mathrm{PD}=15.22 \% \\
\sigma=7.03 \% \\
\mathrm{SEM}=0.19 \% \\
\mathrm{RMSD}=16.77 \%\end{array}$ \\
\hline
\end{tabular}


Table 4. Results of intercomparison of PWV measurements at the Ridge Lab, including number of coincidences $(N)$, correlation coefficient $(R)$, slope of the correlation best fit line $(m)$, mean difference $(\Delta)$, standard deviation of difference $(\sigma)$, standard error of the mean $($ SEM), and root-mean-square difference (RMSD) in mm and \%. Instruments along the $x$ axis (top) are $X$ while instruments along the $y$ axis (side) are $Y$ in Eqs. (1) and (2). A high-resolution version of this table can be found in the Supplement as Table S1.

\begin{tabular}{|c|c|c|c|c|c|}
\hline & $\begin{array}{l}125 \mathrm{HR} \\
(\mathrm{RL})\end{array}$ & $\begin{array}{l}\text { GRUAN } \\
\text { (EWS, RL pc) }\end{array}$ & $\begin{array}{l}\text { RS } \\
\text { (EWS, RL pc) }\end{array}$ & $\begin{array}{l}\text { E-AERI } \\
(\mathrm{RL})\end{array}$ & $\begin{array}{l}\text { SPM } \\
\text { (RL) }\end{array}$ \\
\hline 125HR (RL) & & $\begin{array}{l}N=10 \\
R=0.99 \\
m=1.10 \\
\Delta=-0.44 \mathrm{~mm} \\
\sigma=0.61 \mathrm{~mm} \\
\text { SEM }=0.19 \mathrm{~mm} \\
\text { RMSD }=0.72 \mathrm{~mm} \\
\mathrm{PD}=-5.15 \% \\
\sigma=10.69 \% \\
\mathrm{SEM}=3.38 \% \\
\text { RMSD }=11.38 \%\end{array}$ & $\begin{array}{l}N=65 \\
R=0.98 \\
m=1.07 \\
\Delta=-0.78 \mathrm{~mm} \\
\sigma=0.73 \mathrm{~mm} \\
\mathrm{SEM}=0.09 \mathrm{~mm} \\
\mathrm{RMSD}=1.06 \mathrm{~mm} \\
\mathrm{PD}=-12.19 \% \\
\sigma=8.90 \% \\
\mathrm{SEM}=1.10 \% \\
\mathrm{RMSD}=15.05 \%\end{array}$ & $\begin{array}{l}N=191 \\
R=1.00 \\
m=1.06 \\
\Delta=-0.46 \mathrm{~mm} \\
\sigma=0.42 \mathrm{~mm} \\
\mathrm{SEM}=0.03 \mathrm{~mm} \\
\mathrm{RMSD}=0.62 \mathrm{~mm} \\
\mathrm{PD}=-6.49 \% \\
\sigma=4.29 \% \\
\mathrm{SEM}=0.31 \% \\
\text { RMSD }=7.78 \%\end{array}$ & $\begin{array}{l}N=1304 \\
R=0.99 \\
m=1.16 \\
\Delta=-1.04 \mathrm{~mm} \\
\sigma=0.65 \mathrm{~mm} \\
\text { SEM }=0.02 \mathrm{~mm} \\
\mathrm{RMSD}=1.23 \mathrm{~mm} \\
\mathrm{PD}=-15.10 \% \\
\sigma=6.48 \% \\
\mathrm{SEM}=0.18 \% \\
\mathrm{RMSD}=16.43 \%\end{array}$ \\
\hline GRUAN (EWS, RL pc) & $\begin{array}{l}N=10 \\
R=0.99 \\
m=0.89 \\
\Delta=0.44 \mathrm{~mm} \\
\sigma=0.61 \mathrm{~mm} \\
\text { SEM }=0.19 \mathrm{~mm} \\
\text { RMSD }=0.72 \mathrm{~mm} \\
\mathrm{PD}=5.15 \% \\
\sigma=10.69 \% \\
\mathrm{SEM}=3.38 \% \\
\text { RMSD }=11.38 \%\end{array}$ & & $\begin{array}{l}N=2371 \\
R=1.00 \\
m=1.03 \\
\Delta=-0.15 \mathrm{~mm} \\
\sigma=0.13 \mathrm{~mm} \\
\mathrm{SEM}=0.00 \mathrm{~mm} \\
\mathrm{RMSD}=0.20 \mathrm{~mm} \\
\mathrm{PD}=-3.98 \% \\
\sigma=1.29 \% \\
\mathrm{SEM}=0.03 \% \\
\mathrm{RMSD}=4.18 \%\end{array}$ & $\begin{array}{l}N=68 \\
R=1.00 \\
m=1.02 \\
\Delta=0.00 \mathrm{~mm} \\
\sigma=0.09 \mathrm{~mm} \\
\text { SEM }=0.01 \mathrm{~mm} \\
\text { RMSD }=0.09 \mathrm{~mm} \\
\mathrm{PD}=0.60 \% \\
\sigma=4.18 \% \\
\mathrm{SEM}=0.51 \% \\
\text { RMSD }=4.19 \%\end{array}$ & $\begin{array}{l}N=250 \\
R=0.99 \\
m=1.09 \\
\Delta=-0.62 \mathrm{~mm} \\
\sigma=0.63 \mathrm{~mm} \\
\mathrm{SEM}=0.04 \mathrm{~mm} \\
\mathrm{RMSD}=0.89 \mathrm{~mm} \\
\mathrm{PD}=-7.85 \% \\
\sigma=7.00 \% \\
\mathrm{SEM}=0.44 \% \\
\mathrm{RMSD}=10.51 \%\end{array}$ \\
\hline RS (EWS, RL pc) & $\begin{array}{l}N=65 \\
R=0.98 \\
m=0.89 \\
\Delta=0.78 \mathrm{~mm} \\
\sigma=0.73 \mathrm{~mm} \\
\mathrm{SEM}=0.09 \mathrm{~mm} \\
\mathrm{RMSD}=1.06 \mathrm{~mm} \\
\mathrm{PD}=12.19 \% \\
\sigma=8.90 \% \\
\mathrm{SEM}=1.10 \% \\
\text { RMSD }=15.05 \%\end{array}$ & $\begin{array}{l}N=2371 \\
R=1.00 \\
m=0.97 \\
\Delta=0.15 \mathrm{~mm} \\
\sigma=0.13 \mathrm{~mm} \\
\mathrm{SEM}=0.00 \mathrm{~mm} \\
\mathrm{RMSD}=0.20 \mathrm{~mm} \\
\mathrm{PD}=3.98 \% \\
\sigma=1.29 \% \\
\mathrm{SEM}=0.03 \% \\
\text { RMSD }=4.18 \%\end{array}$ & & $\begin{array}{l}N=124 \\
R=1.00 \\
m=0.97 \\
\Delta=0.14 \mathrm{~mm} \\
\sigma=0.31 \mathrm{~mm} \\
\mathrm{SEM}=0.03 \mathrm{~mm} \\
\mathrm{RMSD}=0.34 \mathrm{~mm} \\
\mathrm{PD}=5.30 \% \\
\sigma=6.03 \% \\
\mathrm{SEM}=0.54 \% \\
\mathrm{RMSD}=8.01 \%\end{array}$ & $\begin{array}{l}N=1038 \\
R=0.99 \\
m=1.08 \\
\Delta=-0.39 \mathrm{~mm} \\
\sigma=0.60 \mathrm{~mm} \\
\text { SEM }=0.02 \mathrm{~mm} \\
\text { RMSD }=0.72 \mathrm{~mm} \\
\mathrm{PD}=-4.31 \% \\
\sigma=7.50 \% \\
\text { SEM }=0.23 \% \\
\text { RMSD }=8.64 \%\end{array}$ \\
\hline E-AERI (RL) & $\begin{array}{l}N=191 \\
R=1.00 \\
m=0.93 \\
\Delta=0.46 \mathrm{~mm} \\
\sigma=0.42 \mathrm{~mm} \\
\mathrm{SEM}=0.03 \mathrm{~mm} \\
\mathrm{RMSD}=0.62 \mathrm{~mm} \\
\mathrm{PD}=6.49 \% \\
\sigma=4.29 \% \\
\mathrm{SEM}=0.31 \% \\
\mathrm{RMSD}=7.78 \%\end{array}$ & $\begin{array}{l}N=68 \\
R=1.00 \\
m=0.97 \\
\Delta=0.00 \mathrm{~mm} \\
\sigma=0.09 \mathrm{~mm} \\
\text { SEM }=0.01 \mathrm{~mm} \\
\text { RMSD }=0.09 \mathrm{~mm} \\
\text { PD }=-0.60 \% \\
\sigma=4.18 \% \\
\text { SEM }=0.51 \% \\
\text { RMSD }=4.19 \%\end{array}$ & $\begin{array}{l}N=124 \\
R=1.00 \\
m=1.02 \\
\Delta=-0.14 \mathrm{~mm} \\
\sigma=0.31 \mathrm{~mm} \\
\mathrm{SEM}=0.03 \mathrm{~mm} \\
\mathrm{RMSD}=0.34 \mathrm{~mm} \\
\mathrm{PD}=-5.30 \% \\
\sigma=6.03 \% \\
\mathrm{SEM}=0.54 \% \\
\mathrm{RMSD}=8.01 \%\end{array}$ & & $\begin{array}{l}N=898 \\
R=0.99 \\
m=1.12 \\
\Delta=-0.47 \mathrm{~mm} \\
\sigma=0.49 \mathrm{~mm} \\
\text { SEM }=0.02 \mathrm{~mm} \\
\mathrm{RMSD}=0.68 \mathrm{~mm} \\
\mathrm{PD}=-5.61 \% \\
\sigma=4.62 \% \\
\mathrm{SEM}=0.15 \% \\
\mathrm{RMSD}=7.27 \%\end{array}$ \\
\hline RL SPM & $\begin{array}{l}N=1304 \\
R=0.99 \\
m=0.84 \\
\Delta=1.04 \mathrm{~mm} \\
\sigma=0.65 \mathrm{~mm} \\
\text { SEM }=0.02 \mathrm{~mm} \\
\text { RMSD }=1.23 \mathrm{~mm} \\
\mathrm{PD}=15.10 \% \\
\sigma=6.48 \% \\
\text { SEM }=0.18 \% \\
\text { RMSD }=16.43 \%\end{array}$ & $\begin{array}{l}N=250 \\
R=0.99 \\
m=0.90 \\
\Delta=0.62 \mathrm{~mm} \\
\sigma=0.63 \mathrm{~mm} \\
\text { SEM }=0.04 \mathrm{~mm} \\
\text { RMSD }=0.89 \mathrm{~mm} \\
\mathrm{PD}=7.85 \% \\
\sigma=7.00 \% \\
\text { SEM }=0.44 \% \\
\text { RMSD }=10.51 \%\end{array}$ & $\begin{array}{l}N=1038 \\
R=0.99 \\
m=0.90 \\
\Delta=0.39 \mathrm{~mm} \\
\sigma=0.60 \mathrm{~mm} \\
\text { SEM }=0.02 \mathrm{~mm} \\
\text { RMSD }=0.72 \mathrm{~mm} \\
\mathrm{PD}=4.31 \% \\
\sigma=7.50 \% \\
\text { SEM }=0.23 \% \\
\text { RMSD }=8.64 \%\end{array}$ & $\begin{array}{l}N=898 \\
R=0.99 \\
m=0.88 \\
\Delta=0.47 \mathrm{~mm} \\
\sigma=0.49 \mathrm{~mm} \\
\text { SEM }=0.02 \mathrm{~mm} \\
\text { RMSD }=0.68 \mathrm{~mm} \\
\text { PD }=5.61 \% \\
\sigma=4.62 \% \\
\text { SEM }=0.15 \% \\
\text { RMSD }=7.27 \%\end{array}$ & \\
\hline
\end{tabular}


Table 5. Results of intercomparison of PWV measurements at OPAL, including number of coincidences $(N)$, correlation coefficient $(R)$, slope of the correlation best fit line $(m)$, mean difference $(\Delta)$, standard deviation of difference $(\sigma)$, standard error of the mean $($ SEM), and root-mean-square difference (RMSD) in mm and \%. Instruments along the $x$ axis (top) are $X$ while instruments along the $y$ axis (side) are $Y$ in Eqs. (1) and (2). A high-resolution version of this table can be found in Table S2.

\begin{tabular}{|c|c|c|c|c|c|c|}
\hline & $\begin{array}{l}\text { E-AERI } \\
(0 \mathrm{PAL})\end{array}$ & $\begin{array}{l}\text { P-AERI } \\
\text { (OPAL) }\end{array}$ & $\begin{array}{l}\text { MWR } \\
\text { (OPAL) }\end{array}$ & $\begin{array}{l}\text { GRUAN } \\
\text { (EWS) }\end{array}$ & $\begin{array}{l}\text { RS } \\
\text { (EWS) }\end{array}$ & $\begin{array}{l}\text { SPM } \\
(0 P A L)\end{array}$ \\
\hline E-AERI (OPAL) & & $N=0$ & $N=0$ & $\begin{array}{l}N=300 \\
R=1.00 \\
m=0.97 \\
\Delta=0.11 \mathrm{~mm} \\
\sigma=0.28 \mathrm{~mm} \\
\mathrm{SEM}=0.02 \mathrm{~mm} \\
\mathrm{RMSD}=0.30 \mathrm{~mm} \\
\mathrm{PD}=0.98 \% \\
\sigma=4.55 \% \\
\mathrm{SEM}=0.26 \% \\
\mathrm{RMSD}=4.65 \%\end{array}$ & $\begin{array}{l}N=475 \\
R=1.00 \\
m=1.01 \\
\Delta=-0.10 \mathrm{~mm} \\
\sigma=0.26 \mathrm{~mm} \\
\mathrm{SEM}=0.01 \mathrm{~mm} \\
\mathrm{RMSD}=0.28 \mathrm{~mm} \\
\mathrm{PD}=-3.20 \% \\
\sigma=4.27 \% \\
\mathrm{SEM}=0.20 \% \\
\mathrm{RMSD}=5.34 \%\end{array}$ & $\begin{array}{l}N=1685 \\
R=0.98 \\
m=1.05 \\
\Delta=-0.43 \mathrm{~mm} \\
\sigma=0.55 \mathrm{~mm} \\
\mathrm{SEM}=0.01 \mathrm{~mm} \\
\mathrm{RMSD}=0.70 \mathrm{~mm} \\
\mathrm{PD}=-3.27 \% \\
\sigma=4.32 \% \\
\mathrm{SEM}=0.11 \% \\
\mathrm{RMSD}=5.42 \%\end{array}$ \\
\hline P-AERI (OPAL) & $N=0$ & & $\begin{array}{l}N=46,054 \\
R=0.99 \\
m=1.09 \\
\Delta=-0.14 \mathrm{~mm} \\
\sigma=0.52 \mathrm{~mm} \\
\mathrm{SEM}=0.00 \mathrm{~mm} \\
\mathrm{RMSD}=0.54 \mathrm{~mm} \\
\mathrm{PD}=1.48 \% \\
\sigma=16.23 \% \\
\mathrm{SEM}=0.08 \% \\
\mathrm{RMSD}=16.30 \%\end{array}$ & $\begin{array}{l}N=108 \\
R=1.00 \\
m=0.93 \\
\Delta=0.02 \mathrm{~mm} \\
\sigma=0.14 \mathrm{~mm} \\
\mathrm{SEM}=0.01 \mathrm{~mm} \\
\mathrm{RMSD}=0.14 \mathrm{~mm} \\
\mathrm{PD}=-0.47 \% \\
\sigma=4.21 \% \\
\mathrm{SEM}=0.41 \% \\
\mathrm{RMSD}=4.22 \%\end{array}$ & $\begin{array}{l}N=639 \\
R=1.00 \\
m=0.97 \\
\Delta=0.00 \mathrm{~mm} \\
\sigma=0.29 \mathrm{~mm} \\
\text { SEM }=0.01 \mathrm{~mm} \\
\mathrm{RMSD}=0.29 \mathrm{~mm} \\
\mathrm{PD}=-1.72 \% \\
\sigma=5.74 \% \\
\mathrm{SEM}=0.23 \% \\
\mathrm{RMSD}=5.99 \%\end{array}$ & $\begin{array}{l}N=7248 \\
R=0.99 \\
m=1.02 \\
\Delta=-0.23 \mathrm{~mm} \\
\sigma=0.42 \mathrm{~mm} \\
\mathrm{SEM}=0.00 \mathrm{~mm} \\
\mathrm{RMSD}=0.48 \mathrm{~mm} \\
\mathrm{PD}=-2.19 \% \\
\sigma=4.13 \% \\
\mathrm{SEM}=0.05 \% \\
\mathrm{RMSD}=4.67 \%\end{array}$ \\
\hline MWR (OPAL) & $N=0$ & $\begin{array}{l}N=46054 \\
R=0.99 \\
m=0.91 \\
\Delta=0.14 \mathrm{~mm} \\
\sigma=0.52 \mathrm{~mm} \\
\mathrm{SEM}=0.00 \mathrm{~mm} \\
\mathrm{RMSD}=0.54 \mathrm{~mm} \\
\mathrm{PD}=-1.48 \% \\
\sigma=16.23 \% \\
\mathrm{SEM}=0.08 \% \\
\mathrm{RMSD}=16.30 \%\end{array}$ & & $\begin{array}{l}N=693 \\
R=0.92 \\
m=0.86 \\
\Delta=0.13 \mathrm{~mm} \\
\sigma=1.21 \mathrm{~mm} \\
\mathrm{SEM}=0.05 \mathrm{~mm} \\
\mathrm{RMSD}=1.21 \mathrm{~mm} \\
\mathrm{PD}=-2.20 \% \\
\sigma=20.47 \% \\
\mathrm{SEM}=0.78 \% \\
\text { RMSD }=20.57 \%\end{array}$ & $\begin{array}{l}N=2527 \\
R=0.98 \\
m=0.90 \\
\Delta=0.19 \mathrm{~mm} \\
\sigma=0.88 \mathrm{~mm} \\
\mathrm{SEM}=0.02 \mathrm{~mm} \\
\mathrm{RMSD}=0.90 \mathrm{~mm} \\
\mathrm{PD}=-1.88 \\
\sigma=17.33 \% \\
\mathrm{SEM}=0.34 \% \\
\text { RMSD }=17.43 \%\end{array}$ & $\begin{array}{l}N=20396 \\
R=0.98 \\
m=0.98 \\
\Delta=0.56 \mathrm{~mm} \\
\sigma=0.59 \mathrm{~mm} \\
\mathrm{SEM}=0.00 \mathrm{~mm} \\
\mathrm{RMSD}=0.82 \mathrm{~mm} \\
\mathrm{PD}=6.87 \% \\
\sigma=7.76 \% \\
\mathrm{SEM}=0.05 \% \\
\mathrm{RMSD}=10.37 \%\end{array}$ \\
\hline GRUAN (EWS) & $\begin{array}{l}N=300 \\
R=1.00 \\
m=1.02 \\
\Delta=-0.11 \mathrm{~mm} \\
\sigma=0.28 \mathrm{~mm} \\
\text { SEM }=0.02 \mathrm{~mm} \\
\text { RMSD }=0.30 \mathrm{~mm} \\
\text { PD }=-0.98 \% \\
\sigma=4.55 \% \\
\text { SEM }=0.26 \% \\
\text { RMSD }=4.65 \%\end{array}$ & $\begin{array}{l}N=108 \\
R=1.00 \\
m=1.07 \\
\Delta=-0.02 \mathrm{~mm} \\
\sigma=0.14 \mathrm{~mm} \\
\mathrm{SEM}=0.01 \mathrm{~mm} \\
\mathrm{RMSD}=0.14 \mathrm{~mm} \\
\mathrm{PD}=0.47 \% \\
\sigma=4.21 \% \\
\mathrm{SEM}=0.41 \% \\
\text { RMSD }=4.22 \%\end{array}$ & $\begin{array}{l}N=693 \\
R=0.92 \\
m=0.99 \\
\Delta=-0.13 \mathrm{~mm} \\
\sigma=1.21 \mathrm{~mm} \\
\mathrm{SEM}=0.05 \mathrm{~mm} \\
\mathrm{RMSD}=1.21 \mathrm{~mm} \\
\mathrm{PD}=2.20 \% \\
\sigma=20.47 \% \\
\mathrm{SEM}=0.78 \% \\
\mathrm{RMSD}=20.57 \%\end{array}$ & & $\begin{array}{l}N=2371 \\
R=1.00 \\
m=1.03 \\
\Delta=-0.19 \mathrm{~mm} \\
\sigma=0.16 \mathrm{~mm} \\
\mathrm{SEM}=0.00 \mathrm{~mm} \\
\mathrm{RMSD}=0.25 \mathrm{~mm} \\
\mathrm{PD}=-3.72 \% \\
\sigma=1.96 \% \\
\mathrm{SEM}=0.04 \% \\
\mathrm{RMSD}=4.20 \%\end{array}$ & $\begin{array}{l}N=264 \\
R=0.99 \\
m=1.05 \\
\Delta=-0.20 \mathrm{~mm} \\
\sigma=0.61 \mathrm{~mm} \\
\mathrm{SEM}=0.04 \mathrm{~mm} \\
\mathrm{RMSD}=0.64 \mathrm{~mm} \\
\mathrm{PD}=-0.72 \% \\
\sigma=5.83 \% \\
\mathrm{SEM}=0.36 \% \\
\mathrm{RMSD}=5.86 \%\end{array}$ \\
\hline RS (EWS) & $\begin{array}{l}N=475 \\
R=1.00 \\
m=0.99 \\
\Delta=0.10 \mathrm{~mm} \\
\sigma=0.26 \mathrm{~mm} \\
\text { SEM }=0.01 \mathrm{~mm} \\
\text { RMSD }=0.28 \mathrm{~mm} \\
\text { PD }=3.20 \% \\
\sigma=4.27 \% \\
\text { SEM }=0.20 \% \\
\text { RMSD }=5.34 \%\end{array}$ & $\begin{array}{l}N=639 \\
R=1.00 \\
m=1.02 \\
\Delta=0.00 \mathrm{~mm} \\
\sigma=0.29 \mathrm{~mm} \\
\text { SEM }=0.01 \mathrm{~mm} \\
\text { RMSD }=0.29 \mathrm{~mm} \\
\text { PD }=1.72 \% \\
\sigma=5.74 \% \\
\text { SEM }=0.23 \% \\
\text { RMSD }=5.99 \%\end{array}$ & $\begin{array}{l}N=2527 \\
R=0.98 \\
m=1.07 \\
\Delta=-0.19 \mathrm{~mm} \\
\sigma=0.88 \mathrm{~mm} \\
\mathrm{SEM}=0.02 \mathrm{~mm} \\
\mathrm{RMSD}=0.90 \mathrm{~mm} \\
\mathrm{PD}=1.88 \% \\
\sigma=17.33 \% \\
\mathrm{SEM}=0.34 \% \\
\text { RMSD }=17.43 \%\end{array}$ & $\begin{array}{l}N=2371 \\
R=1.00 \\
m=0.97 \\
\Delta=0.19 \mathrm{~mm} \\
\sigma=0.16 \mathrm{~mm} \\
\text { SEM }=0.00 \mathrm{~mm} \\
\text { RMSD }=0.25 \mathrm{~mm} \\
\mathrm{PD}=3.72 \% \\
\sigma=1.96 \% \\
\text { SEM }=0.04 \% \\
\text { RMSD }=4.20 \%\end{array}$ & & $\begin{array}{l}N=692 \\
R=0.99 \\
m=1.05 \\
\Delta=-0.07 \mathrm{~mm} \\
\sigma=0.67 \mathrm{~mm} \\
\mathrm{SEM}=0.03 \mathrm{~mm} \\
\mathrm{RMSD}=0.67 \mathrm{~mm} \\
\mathrm{PD}=0.40 \% \\
\sigma=6.63 \% \\
\mathrm{SEM}=0.25 \% \\
\mathrm{RMSD}=6.64 \%\end{array}$ \\
\hline SPM (0PAL) & $\begin{array}{l}N=1685 \\
R=0.98 \\
m=0.92 \\
\Delta=0.43 \mathrm{~mm} \\
\sigma=0.55 \mathrm{~mm} \\
\text { SEM }=0.01 \mathrm{~mm} \\
\text { RMSD }=0.70 \mathrm{~mm} \\
\text { PD }=3.27 \% \\
\sigma=4.32 \% \\
\text { SEM }=0.11 \% \\
\text { RMSD }=5.42 \%\end{array}$ & $\begin{array}{l}N=7248 \\
R=0.99 \\
m=0.96 \\
\Delta=0.23 \mathrm{~mm} \\
\sigma=0.42 \mathrm{~mm} \\
\text { SEM }=0.00 \mathrm{~mm} \\
\text { RMSD }=0.48 \mathrm{~mm} \\
\mathrm{PD}=2.19 \% \\
\sigma=4.13 \% \\
\text { SEM }=0.05 \% \\
\text { RMSD }=4.67 \%\end{array}$ & $\begin{array}{l}N=20396 \\
R=0.98 \\
m=0.98 \\
\Delta=-0.56 \mathrm{~mm} \\
\sigma=0.59 \mathrm{~mm} \\
\text { SEM }=0.00 \mathrm{~mm} \\
\text { RMSD }=0.82 \mathrm{~mm} \\
\text { PD }=-6.87 \% \\
\sigma=7.76 \% \\
\text { SEM }=0.05 \% \\
\text { RMSD }=10.37 \%\end{array}$ & $\begin{array}{l}N=264 \\
R=0.99 \\
m=0.93 \\
\Delta=0.20 \mathrm{~mm} \\
\sigma=0.61 \mathrm{~mm} \\
\text { SEM }=0.04 \mathrm{~mm} \\
\text { RMSD }=0.64 \mathrm{~mm} \\
\mathrm{PD}=0.72 \% \\
\sigma=5.83 \% \\
\text { SEM }=0.36 \% \\
\text { RMSD }=5.86 \%\end{array}$ & $\begin{array}{l}N=692 \\
R=0.99 \\
m=0.93 \\
\Delta=0.07 \mathrm{~mm} \\
\sigma=0.67 \mathrm{~mm} \\
\text { SEM }=0.03 \mathrm{~mm} \\
\text { RMSD }=0.67 \mathrm{~mm} \\
\text { PD }=-0.40 \% \\
\sigma=6.63 \% \\
\text { SEM }=0.25 \% \\
\text { RMSD }=6.64 \%\end{array}$ & \\
\hline
\end{tabular}


(a)

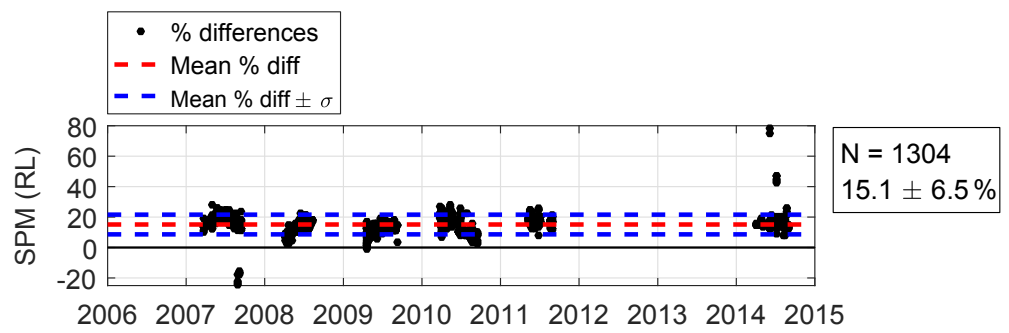

(b)

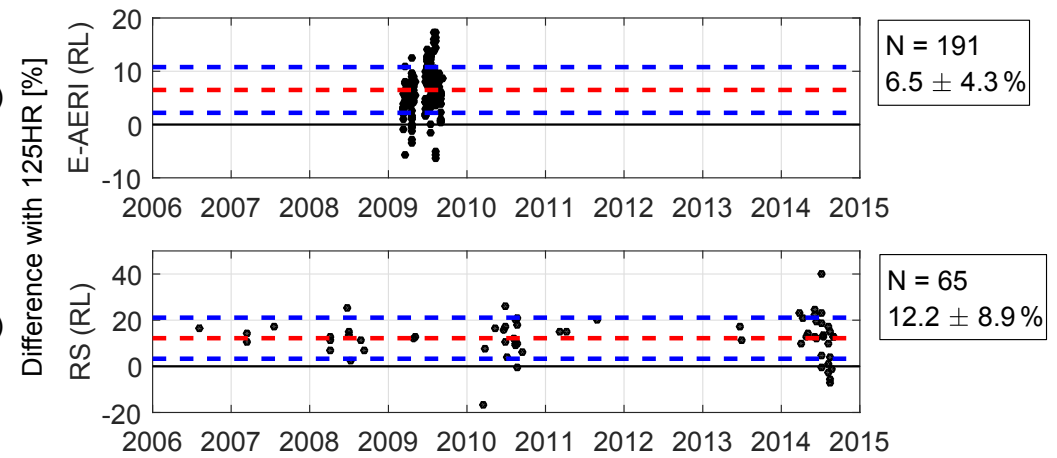

(d)

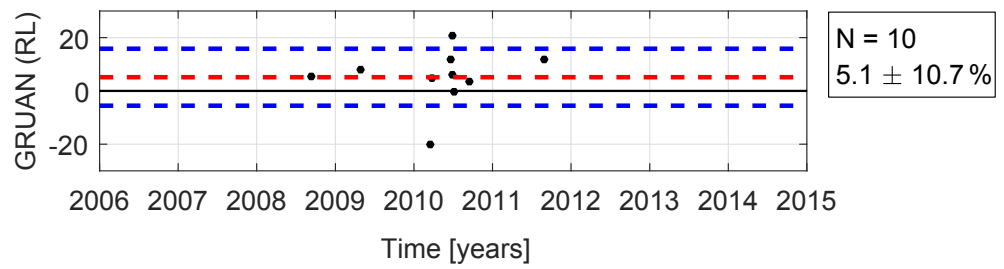

Figure 8. Comparisons of the $125 \mathrm{HR}$ water vapour with PEARL Ridge Lab and Eureka Weather Station instruments. (In Eq. $2, X$ is $125 \mathrm{HR}$ and $Y$ is comparison instrument). The red lines denote the mean difference, while blue lines denote 1 standard deviation above and below the mean difference. The number of comparison pairs and the mean percent difference and standard deviation are noted for each comparison.

\subsection{Summary of PWV comparisons}

Comparisons were conducted between all combinations of the instruments at each site. Not every combination of instruments was shown in detail; this section focused on comparisons between the new FTIR datasets (125HR and AERIs) and co-located instruments. A complete set of correlation plots for available instrument dataset combination at the Ridge Lab is given in Fig. 11. Similarly, OPAL correlation plots are given in Fig. 12. Each row and column of the correlation plots in Figs. 11 and 12 illustrate how well a specific instrument agrees with the other instruments. Presenting all combinations of instruments in this manner allows the differences between the instruments to be observed as they relate to one another and potential biases to be revealed (e.g. the $125 \mathrm{HR}$ is consistently shown to overestimate the water vapour column with respect to other instruments). Comparisons between the SPMs, RS, and GRUAN partial columns between OPAL and RL altitudes are summarized in correlation plots in Fig. 13.

Ridge Lab results are summarized in Table 4. OPAL results are summarized in Table 5. Comparisons between measurements of the partial column between the sites are sum- marized in Table 6. These tables include the number of coincidences found, mean differences, correlation coefficients, standard error of the mean, root-mean-square difference, and correlation plot slopes. High-resolution versions of Fig. 11, Fig. 12, Table 4, and Table 5 are included as Fig. S1, Fig. S2, Table S1, and Table S2, respectively, for easier readability.

\section{Discussion}

Total column comparisons between Eureka water vapour datasets exhibited good overall agreement. All comparisons showed $R$ values of 0.98 or greater, indicating excellent correlation between Eureka water vapour measurements taken by several different instruments. The exception to this is the microwave and GRUAN comparison, for which an $R$ value of 0.92 was observed. Instruments that sample different air masses because of their line of sight, location, measurement timing and length, or sensitivity will show differences because water vapour has high variability over short time spans, altitudes, and distances (Steinke et al., 2015).

The $600 \mathrm{~m}$ altitude difference between the two measurement sites was examined by comparing the partial columns available from the radiosondes, GRUAN, and SPM data. The 
(a)
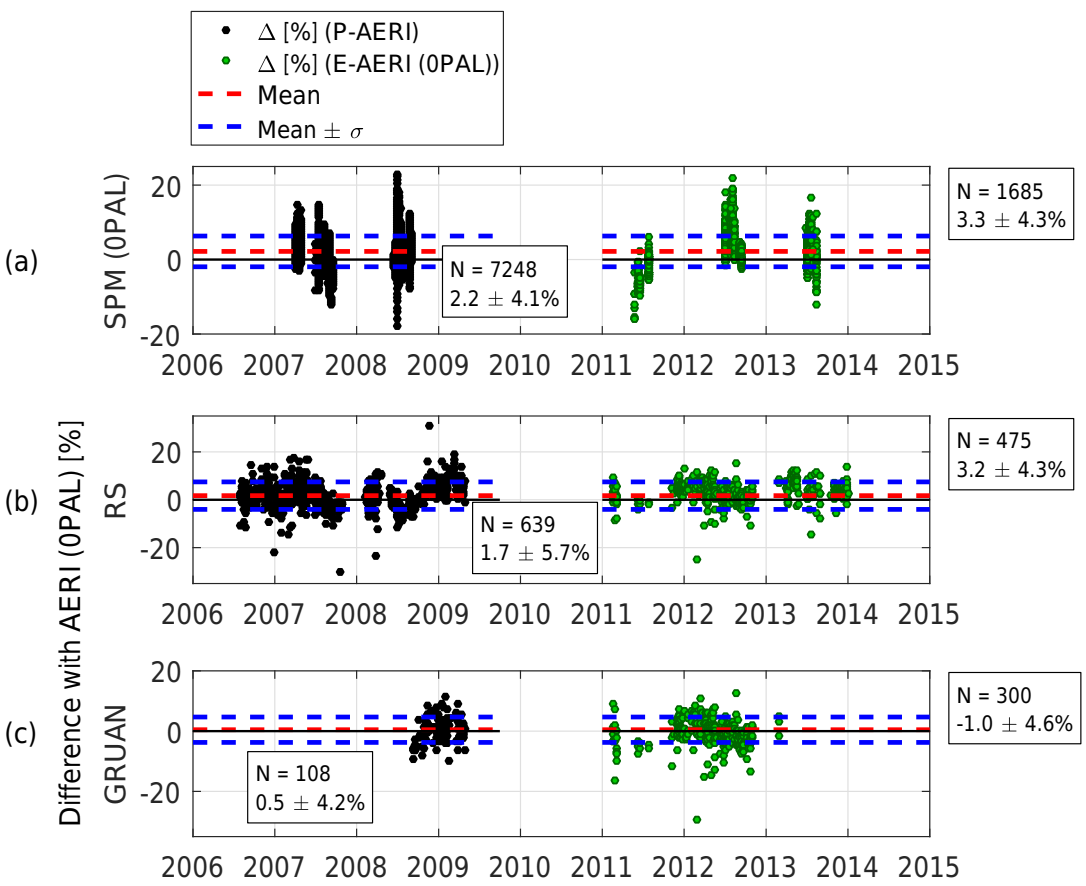

(d)

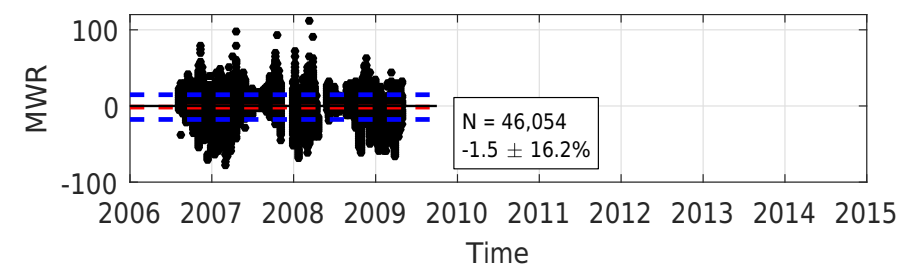

Figure 9. Same as Fig. 8 but for OPAL-based AERI percent difference comparisons with OPAL and EWS instruments. (Percent differences calculated using Eq. (2) where $X$ is P-AERI or OPAL E-AERI.)

magnitude and variability of the difference between measurements using the radiosondes and the SPMs, at the two sites a short distance away $(15 \mathrm{~km})$, demonstrate the significant influence of altitude and meteorological variability on water vapour measurements. This provides useful context for other comparisons of instruments at the Ridge Lab and OPAL sites. Due to the observed magnitude and variability in the partial columns, comparisons between instruments located at different altitudes have not been shown.

\subsection{HR}

The 125HR agreement with other instruments' measured water vapour total columns shows high correlation $(R>0.98)$ and a small overestimation of the water vapour column. Due to the consistency of the observed difference, particularly with trusted datasets such as the GRUAN measurements, the Eureka MUSICA product appears to have a wet bias. The agreement between the 125HR and (smoothed) Eureka radiosondes, for example, is larger difference than expected from the accuracy of the instruments. Given that the radiosondes appear to have a small dry bias of approximately
$4 \%$ based on GRUAN comparisons, the radiosonde measurements suggest the 125HR has a wet bias of around $6 \%$. Furthermore, comparisons between the 125HR and other instruments support this wet bias observation. Agreement between the 125HR and the E-AERI (while co-located at the Ridge $\mathrm{Lab}$ ) shows the $125 \mathrm{HR}$ overestimates water vapour to a similar magnitude. Differences between the 125HR and the Ridge Lab SPM (125HR - SPM) are larger than other comparisons (i.e. $15 \%$ ); however, this result is consistent with other comparisons in the context of SPMs' known underestimation of water vapour by up to $10 \%$. Differences between the $125 \mathrm{HR}$ and RL SPM are usefully informative since the instruments share a solar-viewing measurement geometry, are co-located (within metres), and have closely coincident measurement times.

\subsubsection{Differences between MUSICA retrieval v2012 and v2015 results at Eureka}

The previous MUSICA retrievals (v2012) for the Eureka 125HR showed closer agreement with other instruments than the current MUSICA retrieval version (v2015) used 
(a)

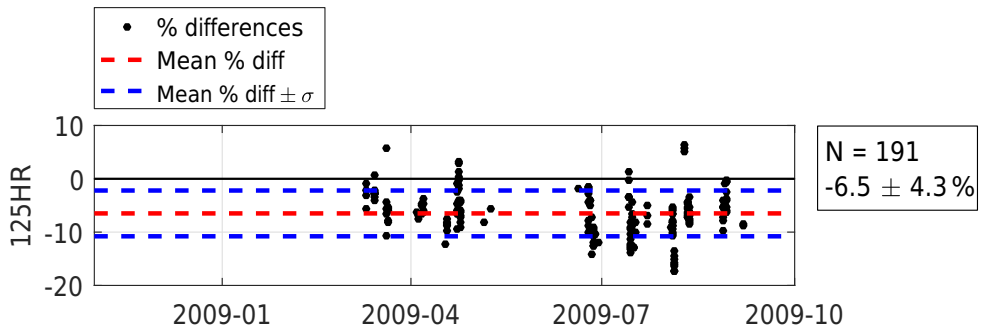

(b)

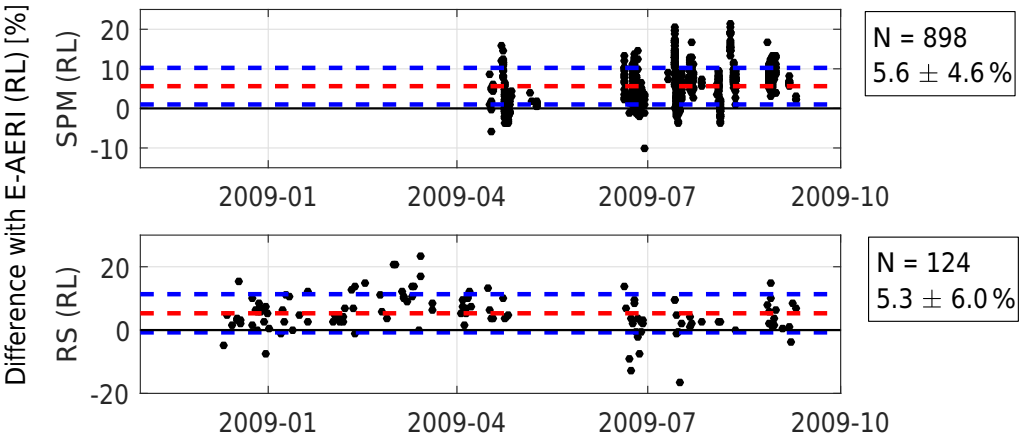

(d)

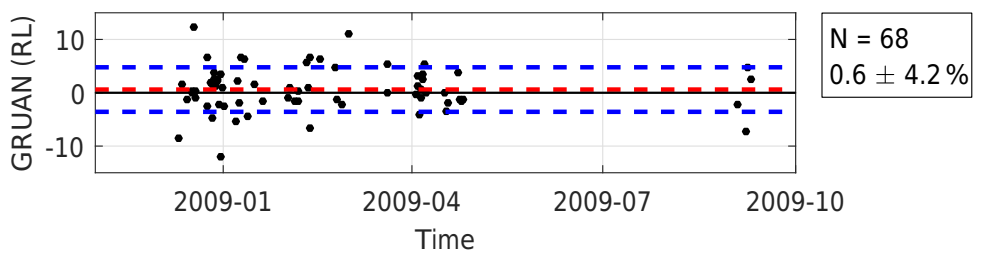

Figure 10. Same as Fig. 8 but for Ridge Lab-based comparisons between the E-AERI and the 125HR, SPM, RS, and GRUAN. Note that the RS and GRUAN datasets are columns calculated starting at the Ridge Lab altitude. (Percent differences calculated using Eq. 2 where $X$ is E-AERI; RL.)

in this study. Agreement between the Eureka v2012 MUSICA retrieval ( $X$ in Eq. 2$)$ and GRUAN $(0.6 \pm 3.3 \%$, $N=10)$, E-AERI (RL; $0.6 \pm 0.3 \%, \mathrm{~N}=191)$, and SPM (RL; $8.7 \pm 0.2 \%)$ are within expected instrument accuracies and biases (e.g. the dry bias of the radiosondes and SPMs). Moreover, the v2012 comparison results are consistent with previous MUSICA intercomparison studies (e.g. Schneider et al., 2010). Table 7 summarizes the water vapour comparisons using the MUSICA v2012 retrieval and a subset of MUSICA v2015 data using the same measurements as the v2012 product.

Two major changes in the v2015 MUSICA retrieval, aimed at improving the network-wide consistency of the MUSICA FTIR products from sites around the world, may have contributed to this change in observed agreement with other High Arctic measurements. First, the a priori profile used for v2015 retrievals was a global average of water vapour, replacing v2012's site-specific a priori profiles based on local radiosonde measurements. For Eureka retrievals, this meant the v2015 a priori profile had more water vapour than is present at Eureka except during summer. Second, the v2015 retrieval replaced two of v2012's spectral windows containing strong absorption features (which had saturated at highhumidity sites such as Wollongong, Australia) with one spec- tral window with weaker absorption lines (Barthlott et al., 2017). It is unlikely that the strong absorption features used in v2012 saturate in High Arctic spectra and likely that they contributed useful information to the retrieval. While MUSICA's change in spectral lines enables consistency across FTIR spectrometers located at sites with very different humidity conditions worldwide, the v2015 spectral windows and global a priori might not be ideal for high-latitude, lowhumidity conditions. Nevertheless, an Arctic bias of a few percent is still a good value for a dataset that is optimized for global consistency.

The difference between the v2015 and v2012 Eureka MUSICA products is $5.6 \pm 0.0 \%$ overall (v2015 - v2012). Differences are greatest during summer and follow a seasonal pattern. Figure 14, a correlation plot for both datasets, shows that the difference increases linearly as humidity increases. This difference is very similar in magnitude to the observed bias relative to other Eureka instruments and suggests changes to the MUSICA retrieval (the selected spectral windows and the usage of a global uniform a priori profile) may have slightly decreased the accuracy at the extreme Arctic site of Eureka. 

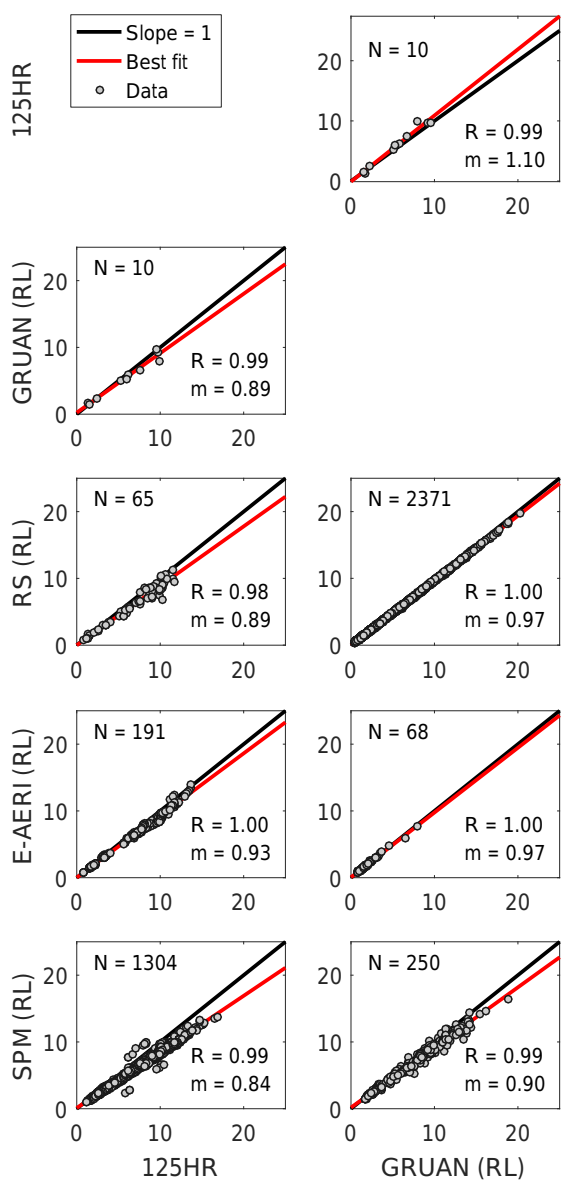
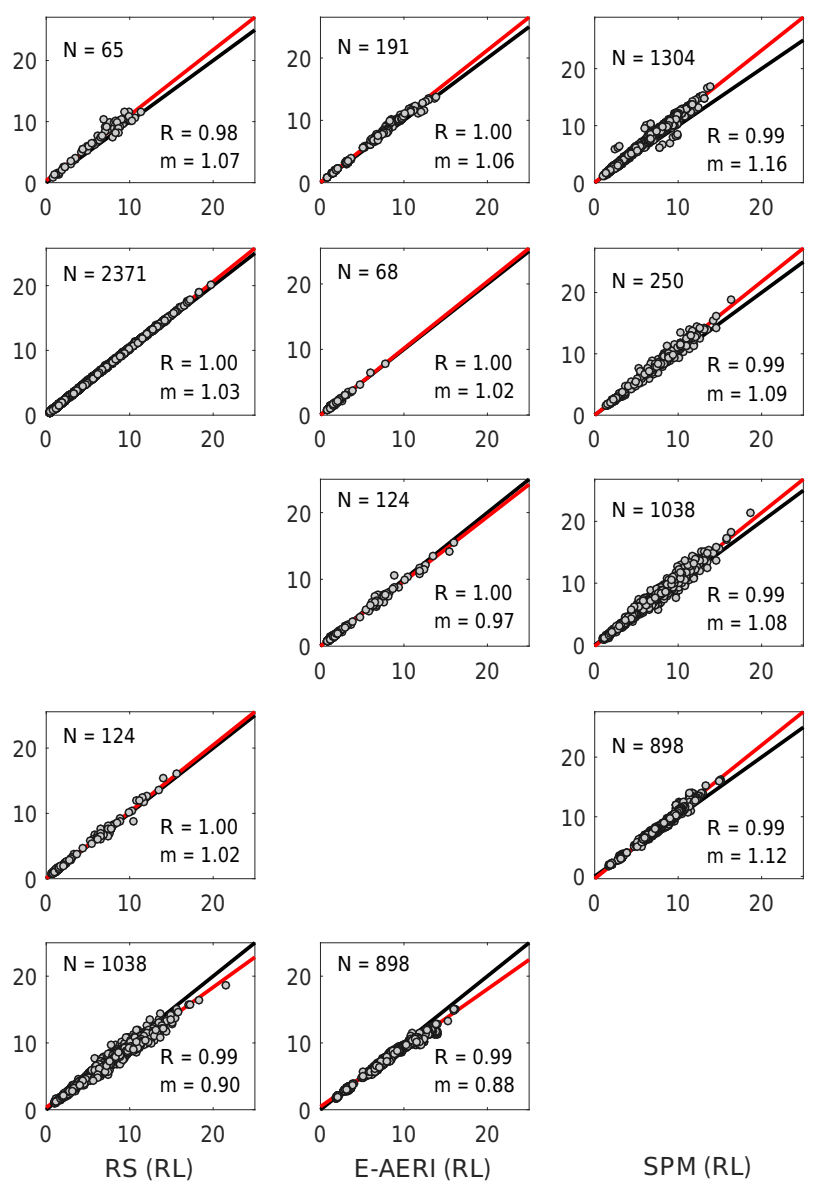

$\operatorname{SPM}(\mathrm{RL})$

Figure 11. Water vapour total column (mm PWV) correlations between instruments at the Ridge Lab. Data used for the radiosonde and GRUAN comparisons with the 125HR have been smoothed with the MUSICA averaging kernels. A high-resolution version of this figure can be found in the Supplement as Fig. S1.

\subsection{AERI instruments}

Close agreement with measurements taken by other colocated Eureka instruments confirms the accuracy of the new AERI water vapour datasets. The P-AERI (located at OPAL) showed agreement with the co-located SPM of $2.2 \pm 0.0 \%$, with the RS of $1.7 \pm 0.2 \%$, with GRUAN of $0.5 \pm 0.4 \%$, and with the MWR of $-1.5 \pm 0.1 \%$ (where $X$ in Eq. 2 is PAERI). The small overestimation of water vapour observed with respect to the SPM and RS may be due to the dry bias of those instruments. The E-AERI showed similar results in comparisons to these datasets and those at the Ridge Lab. These results, particularly the close agreement observed with GRUAN, support the value and use of the new AERI water vapour measurements.

\subsection{Microwave radiometer}

The MWR observes water vapour year-round; thus it has many matches with P-AERI $(N=46,054)$ and RS $(N=2527)$ measurements. The agreement between the
MWR and those instruments, whose measurements are not dependent on sunlight, is close: $1.5 \pm 0.1 \%$ and $1.9 \pm 0.3 \%$, respectively (where MWR is $X$ in Eq. 2). However, the MWR's agreement with co-located datasets has the largest scatter $(\sigma)$ of all comparisons and the largest root-meansquare differences. While this study used $5 \mathrm{~min}$ averages of the MWR measurements to better align with the measurements of comparison instruments, comparisons were also done using $30 \mathrm{~min}$ averages. The results were similar. In addition, comparisons were conducted using a longer time series (i.e. August 2006 to August 2013) than was shown in the main results.

Agreement between the radiosondes and the MWR worsens dramatically after mid-2010. Prior to July 2010 the MWR agreement was consistent with the small known RS dry bias. Starting in fall 2010 and continuing through August 2013 the agreement diminished to $-37.4 \pm 17.0 \%$ ( $\sigma=754.8 \%$ ), with extreme difference outliers on the order of $1000 \%$ (the large relative values are also a consequence of the smallPWV values during Arctic winter). The differences between these time periods of MWR measurements with respect to 

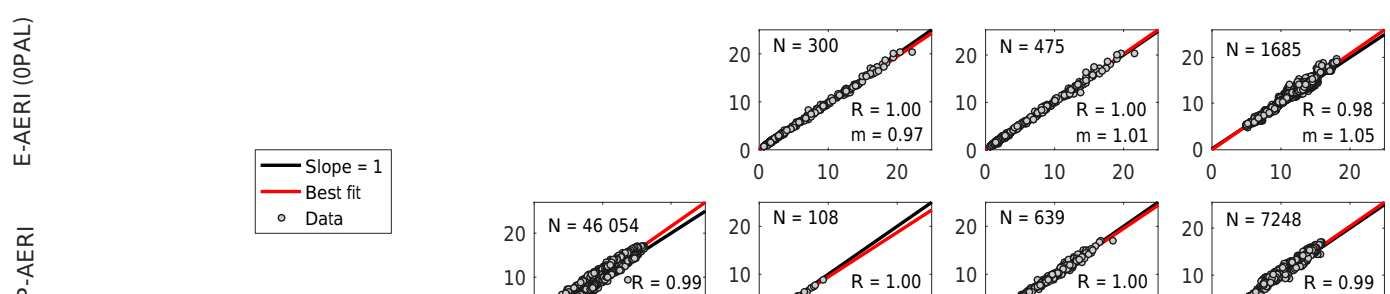

$\stackrel{4}{1}$
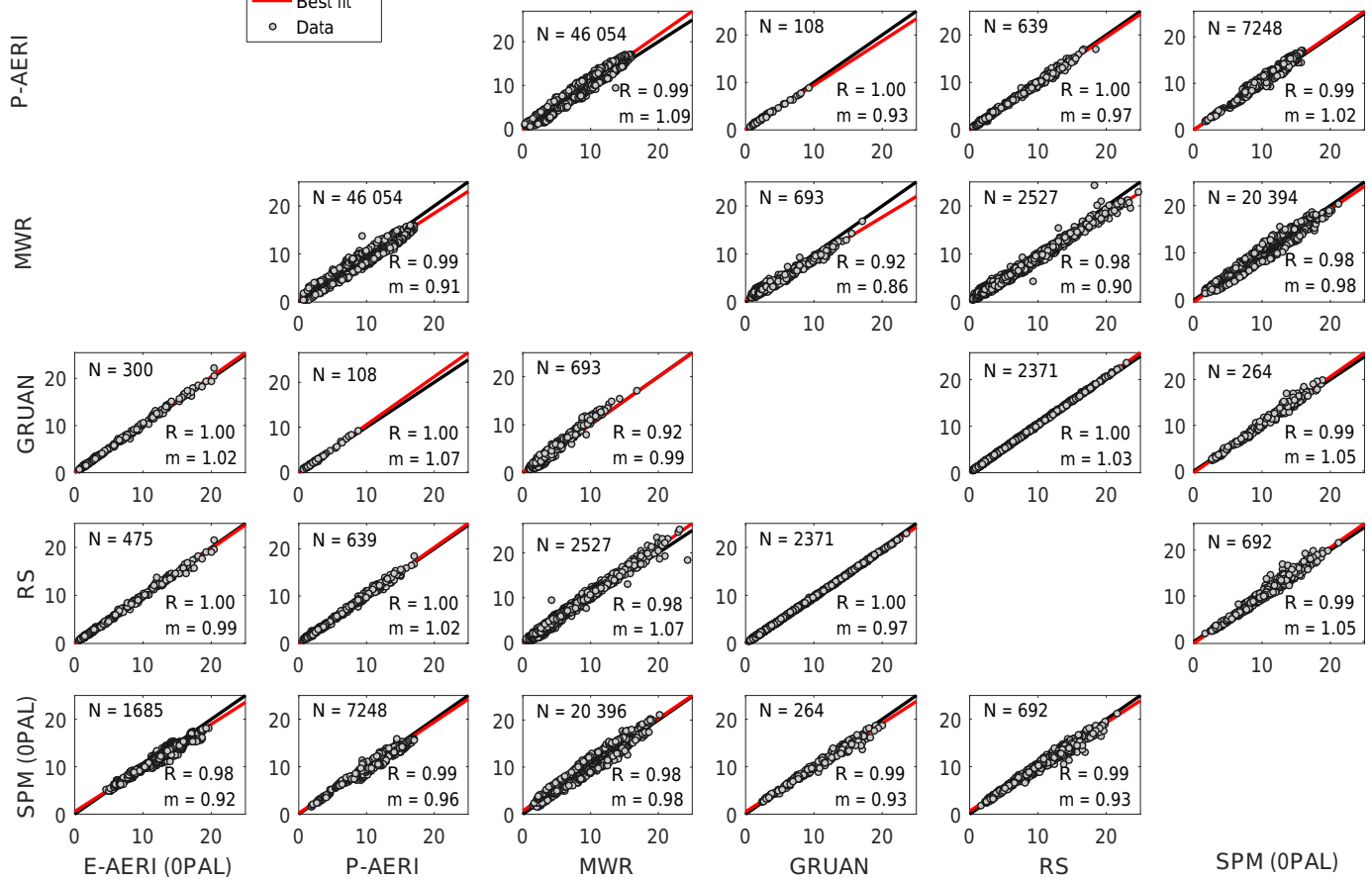

SPM (OPAL)

Figure 12. Water vapour total column (mm PWV) correlations between instruments at OPAL. A high-resolution version of this figure can be found in Fig. S2.
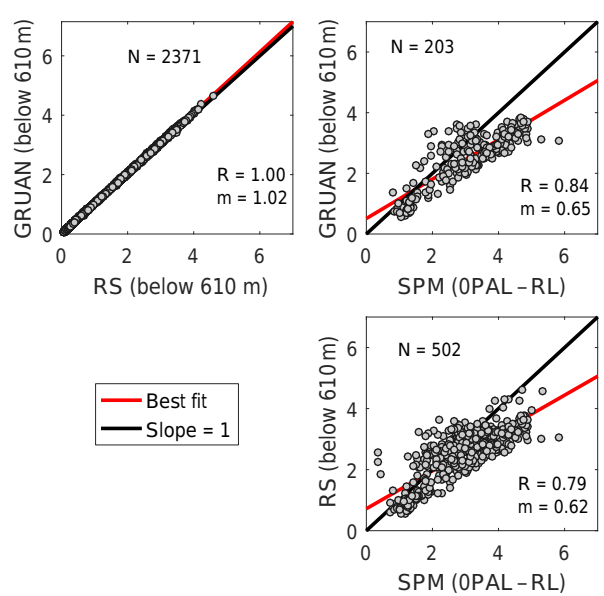

Figure 13. Comparisons between the partial columns of water vapour between the two measurement sites (the Ridge Lab and OPAL) using data from the SPMs and radiosondes.

and radiosondes is shown in Fig. 15. Indeed, after the winter of 2010-2011, MWR water vapour total columns regularly report negative values in low-humidity conditions. Comparisons with other instruments, e.g. E-AERI and GRUAN, show the same difference characteristics.
The accuracy problem of the MWR dataset is likely caused by the limited calibration and maintenance the instrument has received since installation. Poor agreement with the MWR after mid-2010 is interpreted to indicate a problem with the MWR data rather than with other instruments. For example, the P-AERI shows close agreement with the MWR; however, it was only installed at OPAL from 2006 to 2009. This study limited its use of MWR data to the end of June 2010 because of the observed calibration problem revealed by the comparisons. This result demonstrates the value of regularly conducting validation and comparison studies with co-located measurements.

\subsection{Radiosondes}

Comparisons to the GRUAN radiosonde product shows that the standard radiosonde dataset has a small dry bias, particularly in the Eureka summer. This is consistent with other radiosonde studies (e.g. Vömel et al., 2007; Miloshevich et al., 2009). This dry bias helps explain why the radiosonde and GRUAN measurements do not show identical agreement with other instruments. Further, comparison results between the radiosondes and GRUAN are consistent across measurements of the total column, partial column above the Ridge Lab, and partial column below the Ridge Lab. 
Table 6. Results of intercomparison of PWV measurements of partial columns between OPAL and the Ridge Lab, including number of coincidences $(N)$, correlation coefficient $(R)$, slope of the correlation best fit line $(m)$, mean difference $(\Delta)$, standard deviation of difference $(\sigma)$, standard error of the mean (SEM), and root-meansquare difference (RMSD) in $\mathrm{mm}(X-Y)$ and $\%(2 \times(X-Y) /(X+$ $Y) \times 100 \%$ ). Instruments along the $x$ axis (top) are $X$ while instruments along the $y$ axis (side) are $Y$ in Eqs. (1) and (2).

\begin{tabular}{|c|c|c|}
\hline & RS (below $610 \mathrm{~m}$ ) & SPM (OPAL-RS) \\
\hline $\begin{array}{l}\text { GRUAN (below } \\
610 \mathrm{~m} \text { ) }\end{array}$ & $\begin{array}{l}N=2371 \\
R=1.00 \\
m=1.02 \\
\Delta=-0.03 \mathrm{~mm} \\
\sigma=0.03 \mathrm{~mm} \\
\mathrm{SEM}=0.00 \mathrm{~mm} \\
\mathrm{RMSD}=0.04 \mathrm{~mm} \\
\mathrm{PD}=-3.93 \% \\
\sigma=1.70 \% \\
\mathrm{SEM}=0.03 \% \\
\mathrm{RMSD}=4.28 \%\end{array}$ & $\begin{array}{l}N=203 \\
R=0.84 \\
m=0.65 \\
\Delta=0.57 \mathrm{~mm} \\
\sigma=0.63 \mathrm{~mm} \\
\mathrm{SEM}=0.04 \mathrm{~mm} \\
\mathrm{RMSD}=0.85 \mathrm{~mm} \\
\mathrm{PD}=20.74 \% \\
\sigma=22.46 \% \\
\mathrm{SEM}=1.58 \% \\
\mathrm{RMSD}=30.53 \%\end{array}$ \\
\hline $\begin{array}{l}\text { RS (below } \\
610 \mathrm{~m})\end{array}$ & & $\begin{array}{l}N=502 \\
R=0.79 \\
m=0.62 \\
\Delta=0.39 \mathrm{~mm} \\
\sigma=0.62 \mathrm{~mm} \\
\text { SEM }=0.03 \mathrm{~mm} \\
\text { RMSD }=0.73 \mathrm{~mm} \\
\mathrm{PD}=13.68 \% \\
\sigma=25.33 \% \\
\text { SEM }=1.13 \% \\
\text { RMSD }=28.76 \%\end{array}$ \\
\hline
\end{tabular}

\subsection{Sun photometers}

Nearly all comparisons between PEARL SPMs and colocated instruments show an underestimation of water vapour by the SPMs, suggesting that they have a dry bias. This aligns with the existing SPM validation literature (e.g. PérezRamírez, 2014). Results of comparisons between SPM measurements and co-located instruments at the Ridge Lab show greater underestimation of the water vapour column than results using the same instruments at OPAL (e.g. relative to the RS, GRUAN, and E-AERI).

\subsection{Comparison of results to other studies}

Other intercomparison studies have examined water vapour measurement techniques. However, parallels with this study are limited because other studies have been conducted within a different environment, have compared measurements to instruments not available at Eureka (e.g. GPS), and sometimes a different technique has been used to derive water vapour information from the same type of measurement (e.g. FTIR retrievals).
Table 7. Results of comparisons between Ridge Lab instruments and coincident MUSICA v2012 and v2015 datasets, including number of coincidences $(N)$, correlation coefficient $(R)$, slope of the correlation best fit line $(m)$, mean difference $(\Delta)$, standard deviation of difference $(\sigma)$, standard error of the mean (SEM), and rootmean-square difference (RMSD) in $\mathrm{mm}(X-Y)$ and $\%(2 \times(X-$ $Y) /(X+Y) \times 100 \%)$. Instruments along the $x$ axis (top) are $X$ while instruments along the $y$ axis (side) are $Y$ in Eqs. (1) and (2). Highresolution version is available in Table S3.

\begin{tabular}{|c|c|c|}
\hline & $\begin{array}{l}\text { MUSICA } \\
\text { v2012 (coincident } \\
\text { with v2015) }\end{array}$ & $\begin{array}{l}\text { MUSICA } \\
\text { v2015 (coincident } \\
\text { with v2012) }\end{array}$ \\
\hline MUSICA v2015 & $\begin{array}{l}N=2046 \\
R=1.00 \\
m=1.05 \\
\Delta=-0.31 \mathrm{~mm} \\
\sigma=0.19 \mathrm{~mm} \\
\text { SEM }=0.00 \mathrm{~mm} \\
\text { RMSD }=0.37 \mathrm{~mm} \\
\mathrm{PD}=-5.63 \% \\
\sigma=0.96 \% \\
\text { SEM }=0.02 \% \\
\text { RMSD }=5.71 \%\end{array}$ & \\
\hline GRUAN (EWS, RL pc) & $\begin{array}{l}N=10 \\
R=0.99 \\
m=0.94 \\
\Delta=0.17 \mathrm{~mm} \\
\sigma=0.41 \mathrm{~mm} \\
\text { SEM }=0.13 \mathrm{~mm} \\
\text { RMSD }=0.43 \mathrm{~mm} \\
\text { PD }=0.65 \% \\
\sigma=10.44 \% \\
\text { SEM }=3.30 \% \\
\text { RMSD }=9.92 \%\end{array}$ & $\begin{array}{l}N=10 \\
R=0.99 \\
m=0.89 \\
\Delta=0.44 \mathrm{~mm} \\
\sigma=0.61 \mathrm{~mm} \\
\mathrm{SEM}=0.19 \mathrm{~mm} \\
\mathrm{RMSD}=0.72 \mathrm{~mm} \\
\mathrm{PD}=5.15 \% \\
\sigma=10.69 \% \\
\mathrm{SEM}=3.38 \% \\
\text { RMSD }=11.38 \%\end{array}$ \\
\hline RS (EWS, RL pc) & $\begin{array}{l}N=35 \\
R=0.98 \\
m=0.90 \\
\Delta=0.52 \mathrm{~mm} \\
\sigma=0.62 \mathrm{~mm} \\
\text { SEM }=0.10 \mathrm{~mm} \\
\text { RMSD }=0.80 \mathrm{~mm} \\
\mathrm{PD}=8.00 \% \\
\sigma=8.13 \% \\
\text { SEM }=1.37 \% \\
\text { RMSD }=11.37 \%\end{array}$ & $\begin{array}{l}N=35 \\
R=0.99 \\
m=0.87 \\
\Delta=0.78 \mathrm{~mm} \\
\sigma=0.65 \mathrm{~mm} \\
\mathrm{SEM}=0.11 \mathrm{~mm} \\
\mathrm{RMSD}=1.01 \mathrm{~mm} \\
\mathrm{PD}=12.11 \% \\
\sigma=7.71 \% \\
\mathrm{SEM}=1.30 \% \\
\text { RMSD }=14.30 \%\end{array}$ \\
\hline E-AERI (RL) & $\begin{array}{l}N=191 \\
R=1.00 \\
m=0.98 \\
\Delta=0.06 \mathrm{~mm} \\
\sigma=0.33 \mathrm{~mm} \\
\mathrm{SEM}=0.02 \mathrm{~mm} \\
\mathrm{RMSD}=0.34 \mathrm{~mm} \\
\mathrm{PD}=0.58 \% \\
\sigma=4.13 \% \\
\mathrm{SEM}=0.30 \% \\
\text { RMSD }=4.16 \%\end{array}$ & $\begin{array}{l}N=191 \\
R=1.00 \\
m=0.93 \\
\Delta=0.46 \mathrm{~mm} \\
\sigma=0.42 \mathrm{~mm} \\
\mathrm{SEM}=0.03 \mathrm{~mm} \\
\mathrm{RMSD}=0.62 \mathrm{~mm} \\
\mathrm{PD}=6.49 \% \\
\sigma=4.29 \% \\
\mathrm{SEM}=0.31 \% \\
\text { RMSD }=7.78 \%\end{array}$ \\
\hline RL SPM & $\begin{array}{l}N=1109 \\
R=0.99 \\
m=0.89 \\
\Delta=0.60 \mathrm{~mm} \\
\sigma=0.51 \mathrm{~mm} \\
\text { SEM }=0.02 \mathrm{~mm} \\
\text { RMSD }=0.79 \mathrm{~mm} \\
\mathrm{PD}=8.67 \% \\
\sigma=5.85 \% \\
\text { SEM }=0.18 \% \\
\text { RMSD }=10.46 \%\end{array}$ & $\begin{array}{l}N=1109 \\
R=0.99 \\
m=0.85 \\
\Delta=1.00 \mathrm{~mm} \\
\sigma=0.63 \mathrm{~mm} \\
\mathrm{SEM}=0.02 \mathrm{~mm} \\
\mathrm{RMSD}=1.18 \mathrm{~mm} \\
\mathrm{PD}=14.60 \% \\
\sigma=5.71 \% \\
\mathrm{SEM}=0.17 \% \\
\text { RMSD }=15.68 \%\end{array}$ \\
\hline
\end{tabular}




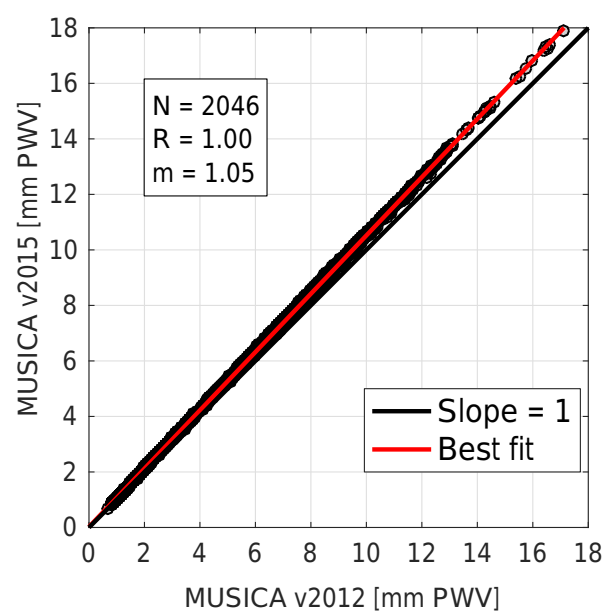

Figure 14. MUSICA v2015 vs. MUSICA v2012 water vapour at Eureka (PEARL Ridge Lab).

Buehler et al. (2012), who compared measurements at Kiruna, Sweden, also used an FTIR spectrometer, radiosondes, and MWR. However, they do not explicitly give the results of any comparisons using the same combination of instruments used in this study. Their FTIR dataset results showed a dry bias at low PWV and a wet bias at high PWV with respect to the GPS. They report that this result is "roughly similar" to the radiosonde comparison with the GPS, but it is not clear how comparable this is to this study's direct FTIR spectrometer (i.e. 125HR) vs. radiosonde results. They find an FTIR spectrometer dry bias with respect to their MWR; however, we did not directly compare the FTIR spectrometer and MWR at PEARL because they are at different altitudes. The observation of an FTIR spectrometer dry bias at Kiruna differs from the observed wet bias seen in this study's examination of the Eureka FTIR MUSICA water vapour retrieval. However, the different FTIR retrieval details may be the source of the difference. Overall, Buehler et al. (2012) note that their instruments agree with $\pm 1 \mathrm{~mm}$ PWV. This is comparable to this study, within which the largest observed difference was $1.0 \mathrm{~mm}$ (125HR vs. SPM).

Palm et al. (2010) conducted a water vapour intercomparison at an Arctic site, Ny Ålesund. Many of the measurements they examined were satellite based. Ground-based FTIR and MWR measurements were compared to radiosoundings. Their results showed that both the FTIR spectrometer and MWR measured systematically smaller water vapour columns than the radiosondes. This differs from the results shown in our study. However, their FTIR retrieval is not identical to the MUSICA retrieval used in the current study and their MWR instrument measures at different frequencies $(142 \mathrm{GHz})$, as it is designed and optimized for measuring stratospheric and mesospheric ozone. Nonetheless, both studies showed high correlation between these instruments and the radiosondes (i.e. greater than $R=0.95$ ).
The water vapour intercomparison study at Izaña by Schneider et al. (2010) examined measurements taken by ground-based FTIR, SPM, GPS, and radiosonde instruments. While their subtropical island mountain location is very different from Eureka, the instrumentation used has parallels to our study. In addition, the Izaña study used a similar FTIR retrieval technique to the MUSICA v2012 discussed here. The Izaña results find the SPM to systematically underestimate the PWV, which is similar to the results of this study. The FTIR spectrometer comparison to the RS shows close agreement, with a mean difference of $0.06 \mathrm{~mm}$ or $-3.3 \%$ (RS FTIR). This is better agreement than observed at Eureka with either MUSICA retrieval version.

The current study adds to existing water vapour intercomparison studies. It offers a comparison of measurements taken at a unique location in the Canadian High Arctic. Moreover, the current study includes results from an extensive set of ground-based instruments and datasets. However, GPS measurements of the water vapour total column are notably common in other studies and measurement sites but are not available for Eureka. It would be useful to add this capability to PEARL's instrument suite, as it would provide an additional water vapour dataset and would enable another avenue for relating results at Eureka to those elsewhere.

\section{Conclusions}

This study compared High Arctic water vapour measurements taken by several different instruments located at Eureka, Nunavut. This large site-wide intercomparison has confirmed the value and reliability of new measurements (i.e. the PEARL 125HR MUSICA and AERI products) and provided a detailed accounting of the comparability of measurements from a variety of commonly used atmospheric monitoring instruments.

The accuracy of the MUSICA dataset derived from Eureka $125 \mathrm{HR}$ spectra is supported by comparisons with coincident measurements taken at Eureka. The MUSICA v2015 product shows close agreement with other instruments; however, it shows a small wet bias, which was not observed in comparisons using the previous MUSICA v2012 retrieval. Changes to the MUSICA retrieval intended to balance the needs of globally distributed FTIR spectrometer sites appears to have created a small wet bias at this extremely dry high-latitude site. This underscores the challenge in assuring consistency across global observation networks as well as the performance of measurement techniques operating across a wide range of conditions.

This result affirms the conclusions of previous intercomparison studies at other MUSICA sites that $125 \mathrm{HR}$ measurements can yield reliable and precise information about atmospheric water vapour total columns. Moreover, these results also support the use of 125HR measurements taken beyond MUSICA's standard $78.5^{\circ}$ SZA limit. Comparisons in this 


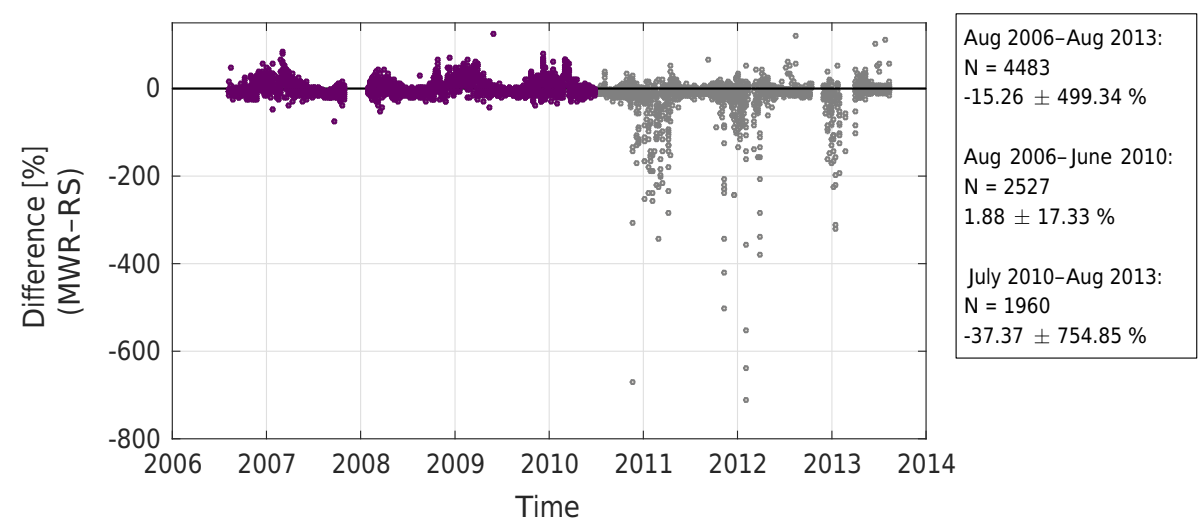

Figure 15. Comparisons between the MWR and radiosondes. Data used in this study are in purple; data that are available but not used due to calibration and quality concerns are in grey. The change in agreement from fall 2010 onwards is clearly evident. The plot scale cuts off extreme outliers.

study included SZAs up to $85^{\circ}$ without sacrificing the consistency with other instruments' measurements. Relaxing this constraint is useful for polar sites. Observed differences between the 125HR and other instruments are consistent with well-understood measurement technique biases and differences in observation geometry.

The moderate number of coincident measurements with radiosondes presented in this study suggests that the $125 \mathrm{HR}$ offers accurate information about water vapour abundances in the troposphere. The assertion of Schneider et al. (2016) that MUSICA retrievals offer approximately $10 \%$ accuracy is affirmed; however, a small wet bias of 5 to $6 \%$ is observed at Eureka.

The new AERI datasets presented in this study showed close agreement with other Eureka instruments (e.g. agreement better than $4 \%$ relative to GRUAN). AERI measurements thus offer reliable continuous observations of atmospheric water vapour total columns without reliance on sunlight. Adding this capability to existing water vapour observations is especially valuable at Eureka because there is no sunlight between mid-October and late February and for parts of the day during spring and fall. 125HR and AERI retrievals thus offer a reliable, accurate, and frequent source of information about atmospheric water vapour at Eureka. Application of the Eureka AERI water vapour retrieval algorithm to other Arctic AERI sites (e.g. Barrow, Alaska, and Summit, Greenland) would be a useful next step. A standardized AERI water vapour dataset across the Arctic region would be a valuable addition to existing water vapour measurements and enable a comparison between Eureka and other Arctic AERI water vapour measurements.

The World Meteorological Organization (WMO) GCOS has set out goals for the accurate measurement of essential climate variables, including water vapour. The GCOS goal for water vapour total columns is measurement accuracy within $1 \mathrm{~kg} \mathrm{~m}^{-2}$ (equivalent to $1 \mathrm{~mm}$ PWV; WMO, 2017) and within $2 \%$ (WMO, 2016). The comparisons shown in this work between the 125HR and AERI datasets and those of other instruments at Eureka show mean differences less than $1 \mathrm{~mm}$ PWV. The P-AERI shows mean agreement within $2 \%$ of other instruments. Measurements from other instruments do not show agreement within this threshold. This result motivates continued work on FTIR retrievals to attain accurate measurements of water vapour total columns for use by the climate and atmospheric community.

Radiosonde measurements are often used a reference because of their reliable and well-understood character, as well as their high vertical resolution. The GRUAN product resulting from recent processing the raw radiosondes data reveals that the Eureka radiosondes measurements are affected by a small dry bias (approximately $4 \%$ ), which is largest in the summer. This should be taken into account when using radiosondes as a reference for climatological and atmospheric investigations. Further, the additional information and accuracy offered by the GRUAN processing offers clear benefits to observations at Eureka. Participation in the GRUAN network would be advantageous for the site.

PEARL's MWR showed reasonable correlations and agreement with other datasets period to mid-2010; however, under low-PWV conditions MWR measurements after fall 2010 show significant disagreement with other co-located instruments. The comparisons conducted in this work demonstrate the need to continuously validate data, especially data resulting from experiments in remote locations where maintenance and calibration opportunities are difficult and infrequent.

No single instrument is capable of capturing complete information about atmospheric water vapour at all times. There are limits to all measurement techniques. Moreover, most instruments have downtime due to technical challenges, particularly when operating in a harsh environment such as the High Arctic. The widespread agreement across the suite of Eureka instruments with different observation strengths offers a valuable capability to collectively measure water 
vapour abundances and variability in the Canadian High Arctic. The agreement seen between total column measurements suggest that a unified water vapour product at Eureka could be explored. This appears especially promising with a reliable AERI product available to fill in the polar night measurement gap left by the SPMs and 125HR, as well as the large temporal gaps (i.e. $12 \mathrm{~h}$ ) between radiosonde measurements.

A follow-up study of Eureka radiosonde and MUSICA water vapour profiles compared to a suite of Eurekacoincident satellite datasets is planned for the future. Other possible topics for continued study include the analysis of trends at Eureka and a climatological comparison of Eureka to water vapour measured at other Arctic sites.

Data availability. The PEARL 125HR FTIR v2015 water vapour dataset is described in Barthlott et al. (2017) and is available at: https://doi.org/10.5281/zenodo.48902 and ftp://ftp.cpc.ncep.noaa. gov/ndacc/MUSICA/ The SPM datasets at the RL and OPAL are available through the AERONET online data archive, at: https: //aeronet.gsfc.nasa.gov/ For access to other datasets used in this study, please contact the authors. 


\section{Appendix A: AERI retrieval description}

The AERI water vapour retrieval involves the following steps:

1. An atmospheric profile is created describing the atmospheric state at each radiosonde time.

2. The error budgets for the measured and simulated downwelling radiances are determined.

3. The frequency-dependent uncertainties in measured and simulated downwelling radiances are used to select the best set of frequencies for retrieving water vapour amounts.

4. Clear-sky time periods are identified.

5. The precipitable water vapour is retrieved by finding the scale factor that minimizes the difference between measured and simulated downwelling radiances, where the scale factor scales the first-guess water vapour profile.

These steps are described below, highlighting differences from Rowe et al. (2008).

\section{A1 Creation of atmospheric profiles}

First-guess atmospheric profiles are created using height, pressure, temperature, and water vapour amounts from the radiosondes. Above about $10 \mathrm{~km}$, the water vapour amount is fixed to 5 ppmv. Ozone is determined from ozonesonde flights made at Eureka. Other trace gases, including $\mathrm{CO}_{2}$ (Conway et al., 2011), $\mathrm{N}_{2} \mathrm{O}, \mathrm{CH}_{4}$, and chlorofluorocarbons (CFC-11, CFC-12, CFC-113), are based on surface measurements made at Alert, Nunavut, or Barrow, Alaska, through the NOAA Earth System Research Laboratory (ESRL) Global Monitoring Division. Mixing ratios are assumed to be constant with height. For other trace gases, and for values above the top of the soundings, the subarctic summer and winter standard atmosphere models of McClatchey et al. (1972) are used. The profiles are interpolated onto a layered model atmosphere extending from 0 to $60 \mathrm{~km}$ with 60 layers that get progressively closer together moving down from $60 \mathrm{~km}$ to the surface.

\section{A2 Uncertainties in measured and simulated radiances}

After developing atmospheric profiles, the error budgets of the measured downwelling radiances are estimated as described in Rowe et al. (2008). Errors are similar in spectral shape to the case shown in Rowe et al. (2008; Fig. 3) and vary seasonally with similar magnitudes in winter (maximum of about $0.15 \mathrm{RU}$ ) to roughly double in summer (maximum of about $0.30 \mathrm{RU}$, where $1 \mathrm{RU}$ is 1 radiance unit, defined as $\left.1 \mathrm{RU}=1 \mathrm{~mW} \times\left(\mathrm{m}^{2} \mathrm{srcm}^{-1}\right)^{-1}\right)$. The noise level for the E-AERI is lower than $0.4 \mathrm{RU}$ (Mariani et al., 2013). For the P-AERI, the noise level near $900 \mathrm{~cm}^{-1}$, after noise filtering, is estimated to be $\sim 0.070 \mathrm{RU}$ in winter, increasing to $\sim 0.15 \mathrm{RU}$ in summer. The noise level in spectral regions used to retrieve water vapour, where the downwelling radiance is considerably stronger, may be up to twice as large as in the window region (Turner et al., 2006).

Uncertainties in simulated downwelling radiances are determined for monthly-averaged atmospheric profiles. Downwelling radiances are simulated using the line-by-line radiative transfer model (LBLRTM; Clough et al., 2005) for the first-guess atmospheric profile and then with each atmospheric constituent perturbed by its estimated uncertainty. The difference is calculated to give the uncertainty in the simulated radiance due to the uncertainty in the constituent. The uncertainty in temperature is assumed to be $0.5 \mathrm{~K}$ and is calculated as a bias in the entire profile. The uncertainty in $\mathrm{CO}_{2}$ is assumed to be $2 \%$. For other trace gases, including $\mathrm{HNO}_{3}, \mathrm{~N}_{2} \mathrm{O}, \mathrm{CH}_{4}, \mathrm{O}_{3}, \mathrm{CO}, \mathrm{C}_{2} \mathrm{H}_{2}, \mathrm{HCN}, \mathrm{CCL}_{4}, \mathrm{CFC}-11$, CFC-12, and CFC-113, an uncertainty of $10 \%$ is assumed. In addition, uncertainties of $30 \%$ in the continuum of water vapour emission between strong lines due to self-broadening and foreign broadening are assumed. The combined uncertainties in measured and simulated downwelling radiances are calculated assuming the sources of error are uncorrelated (that is, by taking the square root of the sum of the square errors), resulting in combined errors, excluding noise, that vary spectrally and seasonally between 0.07 and $\sim 2.5 \mathrm{RU}$.

\section{A3 Identification of wave numbers}

To identify the best frequencies for retrieving water vapour, the expected uncertainty in the total column water vapour that would be retrieved at each frequency is determined. The uncertainty is calculated as follows. First, the sensitivity of the downwelling radiance to changes in the total column of water vapour is determined by calculating the change in simulated radiance for a $5 \%$ change in the first-guess water vapour profile (i.e. a $5 \%$ change is used in all layers). These values are then used to determine the percent change in water vapour per change in radiance. Next, the percent change in water vapour per change in radiance is multiplied by the combined uncertainty in the measured and simulated downwelling radiances, giving the expected uncertainty in water vapour at each frequency. Note that this uncertainty has units of percentage of the first-guess water vapour profile or, equivalently, percentage of the first-guess total column of water vapour. Finally, the 100 frequencies where this uncertainty is the lowest are selected for monthly-averaged atmospheric profiles. Thus the chosen frequencies vary by month. They include frequencies in the microwindows between strong lines from 500 to $600 \mathrm{~cm}^{-1}$, in the atmospheric window between 700 and $1100 \mathrm{~cm}^{-1}$, and in the wing of the strong water vapour absorption feature centred at $1600 \mathrm{~cm}^{-1}$, between 1100 and $1400 \mathrm{~cm}^{-1}$. 


\section{A4 Identification of clear-sky time periods}

To identify clear-sky time periods, we compare observed to simulated clear-sky radiances between 898.0 and $905.7 \mathrm{~cm}^{-1}$, where emission from trace gases is extremely weak and therefore any cloud emission should be evident. To choose a threshold for the comparison, we use as a guide cases where the simulated radiance is lower than the observed radiance, assuming such cases are cloud free. For the P-AERI, the standard deviation of the difference between observed and simulated radiances for such cases is $0.4 \mathrm{RU}$, while for the E-AERI it is $0.8 \mathrm{RU}$ (perhaps due in part to the larger noise of the E-AERI). Thus these values serve as radiance thresholds for clear-sky: if the observation is within 0.4 (P-AERI) or 0.8 (E-AERI) RU between 898.0 and $905.7 \mathrm{~cm}^{-1}$ the scene is assumed to be cloud free. If these biases are due to clouds, maximum errors in retrieved water vapour would be 0.6 to $3 \%$ for P-AERI (summer to winter), and $5-7 \%$ for E-AERI (summer to winter). However, given the magnitude of the negative errors, these differences are more likely due to differences in the water vapour itself as well as sources of error that have already been accounted for.

\section{A5 Water vapour retrieval}

To retrieve the water vapour total column from the AERI measurements, a straightforward method would be to do the following for each AERI spectral measurement: (a) calculate the atmospheric profile, including the first-guess water vapour column amount; (b) scale the water vapour profile by a scale factor; (c) run the LBLRTM simulation and reduce the spectral resolution to that of the AERI; (d) calculate the weighted mean between the simulation and the AERI spectrum; (e) repeat (b)-(d) to find the minimum weighted mean difference; and (f) compute the total column of water vapour (as precipitable water vapour) from the scaled-water vapour profile. However, due to the large number of AERI spectra (high temporal sampling), the computational cost of so many LBLRTM calculations is quite high. Thus, a method was developed to accelerate the radiative transfer. While it is slightly more complicated, it is functionally nearly equivalent to repeated LBLRTM runs.

The alternative method devised for retrieving the total column water vapour relies on a forward model that takes as input layer optical depths that are interpolated in time rather than water vapour profiles that have been interpolated in time. This is computationally much faster because calculation of optical depths is the time-consuming calculation in the LBLRTM. With this method, optical depths need only be computed at the radiosonde times. After interpolating optical depths and temperature profiles to the AERI measurement times, the radiative transfer can be quickly computed. The forward model is as follows:

$F=\left[\sum_{i=1}^{N} I_{i}(v) t_{i-1}(v)\right] \otimes \operatorname{sinc}(v)$,

where $I$ is the layer radiance, defined by Clough et al. (1992; see Eqs. 14 and 15; see also Rowe, 2004), $t$ is the transmittance below the layer, and the radiances are summed over layers $i$. The frequency-dependent downwelling radiance is convolved with a sinc function to reduce the resolution to that of the AERI. Both $I$ and $t$ depend on the layer optical depths. In particular, $I$ is approximated as

$I=\left(1-e^{-\tau}\right) B(\tau)$,

where $\tau$ is the total layer optical depth and $B$ is calculated in the same manner as Clough et al. (1992; Eq. 15). Furthermore,

$t_{i-1}=e^{-\widetilde{\tau}_{i-1}}$,

where the tilde indicates that the optical depth is from the surface to layer $i-1$; surface-to-layer optical depths are calculated by summing layer optical depths. The layer optical depths are calculated according to

$\tau=\tau_{\mathrm{g}}+\tau_{\mathrm{w}}+\tau_{\mathrm{s}}$,

where $\tau_{\mathrm{g}}$ is the layer optical depth of all gases excluding water vapour, $\tau_{\mathrm{w}}$ is the optical depth due to water vapour, excluding the "self-broadened continuum", and $\tau_{\mathrm{s}}$ is the optical depth due to the self-broadened continuum of water vapour. (A description of the water vapour continuum is given by Mlawer et al., 2012; see also Rowe et al., 2006, 2008.)

Optical depths $\tau_{\mathrm{g}}$ and $\tau_{\mathrm{w}}$ are determined at AERI measurement times $t_{\mathrm{M}}$ by linearly interpolating values at radiosonde times $t_{1}$ and $t_{2}$ using weights $w_{1}$ and $w_{2}$ :

$\tau_{\mathrm{g}}\left(t_{\mathrm{M}}\right)=\tau_{\mathrm{g}}\left(t_{1}\right) w_{1}+\tau_{g}\left(t_{2}\right) w_{2}$,

and

$\tau_{\mathrm{w}}\left(t_{\mathrm{M}}\right)=s\left[\tau_{\mathrm{w}}\left(t_{1}\right) w_{1}+\tau_{\mathrm{w}}\left(t_{2}\right) w_{2}\right]$,

where the parentheses indicate functionality and brackets indicate multiplication.

The layer optical depths $\tau_{\mathrm{g}}\left(t_{1}\right), \tau_{\mathrm{g}}\left(t_{2}\right), \tau_{\mathrm{w}}\left(t_{1}\right)$, and $\tau_{\mathrm{w}}\left(t_{2}\right)$ are calculated using the LBLRTM (Clough et al., 2005; Mlawer et al., 2012). Note that the weak dependence of absorption coefficients on temperature introduces a very small error due to interpolating optical depths in time; this error is expected to be negligible compared to other sources of error.

The optical depth for the self-broadened continuum is not included in $\tau_{\mathrm{w}}$ because $\tau_{\mathrm{s}}$ depends on the square of the water vapour concentration, whereas $\tau_{\mathrm{w}}$ depends linearly on the water vapour concentration. Fortunately, the self-broadened continuum of water vapour is smooth and follows a simple parametrization so that $\tau_{\mathrm{s}}\left(t_{\mathrm{M}}\right)$ can be calculated at each 
AERI measurement time using the empirical formula given by Mlawer et al. (2012; see also Rowe et al., 2006, 2008).

Thus the revised method is as follows. (a) Calculate a first-guess atmospheric profile, including the first-guess water vapour profile, at radiosonde times. (b) Calculate optical depths $\tau_{\mathrm{g}}$ and $\tau_{w}$ for each model atmospheric layer at the radiosonde times $\left(t_{1}\right.$ and $t_{2}$ ), using the LBLRTM. (c) Linearly interpolate the layer optical depths, temperatures, and the water vapour profile to the AERI measurement time (e.g. Eqs. A5 and A6; using weights $w_{1}$ and $w_{2}$ ). (d) Choose a scale factor and scale the water vapour profile and $\tau_{\mathrm{w}}$ by the scale factor (Eq. A6). (e) Based on the scaled water vapour profile, calculate $\tau_{\mathrm{s}}$ at the AERI measurement time. (f) Sum each layer $\tau_{\mathrm{g}}, \tau_{\mathrm{w}}$, and $\tau_{\mathrm{s}}$ to give the total layer optical depth (Eq. A4). (g) Perform the radiative transfer, using the summed layer optical depths and the temperature profile as inputs, and reduce the resolution of the simulation to that of the measurement (Eqs. A1-A3). (h) Repeat steps (d)(g) to find the scale factor that minimizes the weighted mean difference between measured and simulated downwelling radiance. (i) Compute the total column of water vapour (as precipitable water vapour) from the scaled-water vapour profile.

Step (h) is performed using golden section search and parabolic interpolation to find the scale factor to a tolerance well below the uncertainty level. Cases with minimum weighted mean differences greater than expected uncertainties are removed as part of quality control (here, a threshold of $2 \mathrm{RU}$ removed 150 cases). The frequency-dependent uncertainties and the weights are also used to determine the uncertainty in the retrieved scale factor following standard uncertainty analysis, resulting in uncertainties in retrieved PWV of 3 to $11 \%$ for summer to winter cases. 


\section{The Supplement related to this article is available online at https://doi.org/10.5194/amt-10-2851-2017-supplement.}

Author contributions. DW led the study, acquired 125HR measurements, gathered the datasets, calculated the comparisons between the datasets, created the figures and tables, and wrote the manuscript. KS advised and guided the work and provided significant editing, advice, and comments. MS performed the $125 \mathrm{HR}$ retrievals following the MUSICA technique and offered detailed comments. PR performed the AERI retrievals and wrote the description of the AERI retrieval, provided in the Appendix and offered helpful comments. ZM acquired measurements using the EAERI, and offered comments on the AERI instruments and related results. AS assisted with the development and implementation of the AERI retrieval technique. HV processed the raw Eureka radiosonde measurement files according to the GRUAN technique. KAW contributed insight into the ACE-FTS dataset originally part of this study, as well as helpful comments on the manuscript. CS contributed the ACE-MAESTRO water vapour dataset originally part of this study, as well as helpful comments on the manuscript and discussions about the meteorological conditions at Eureka. CT contributed insight and comments regarding the ACE-MAESTRO measurement comparisons. TU contributed the microwave radiometer dataset and offered helpful discussion about that dataset. JR supported and facilitated operations of the PEARL instruments whose measurements were used in this study.

Competing interests. The authors declare that they have no conflict of interest.

Special issue statement. This article is part of the special issue "Twenty-five years of operations of the Network for the Detection of Atmospheric Composition Change (NDACC) (AMT/ACP/ESSD inter-journal SI)". It is not associated with a conference.

Acknowledgements. CANDAC/PEARL funding partners are the Arctic Research Infrastructure Fund, Atlantic Innovation Fund/Nova Scotia Research Innovation Trust, Canadian Foundation for Climate and Atmospheric Science, Canada Foundation for Innovation, Canadian Space Agency (CSA), Environment and Climate Change Canada (ECCC), Government of Canada International Polar Year, Natural Sciences and Engineering Research Council (NSERC), Ontario Innovation Trust, Ontario Research Fund, Indian and Northern Affairs Canada, and the Polar Continental Shelf Program. Spring visits to PEARL were made as part of the Canadian Arctic ACE Validation Campaigns supported by CSA, ECCC, NSERC, and the Northern Student Training Program. This work also received funding from the NSERC CREATE Training Program in Arctic Atmospheric Science, the NSERC-supported PAHA project, and the CSA-supported CAFTON project.

The authors would like to thank PEARL Site Manager Pierre Fogal and the CANDAC operators for logistical and operational support at Eureka; ECCC for providing the radiosonde data;
AERONET/AEROCAN for sun photometer data; Rodica Lindenmaier, Rebecca Batchelor, and Joseph Mendonca for 125HR measurements; Mareile Wolff for early E-AERI measurements; and CANDAC data manager Yan Tsehtik. Chris Cox at NOAA and Patrick Sheese at the University of Toronto offered helpful comments.

The authors wish to thank the staff at ECCC's Eureka Weather Station for logistical and on-site support.

MUSICA has been funded by the European Research Council under the European Community's Seventh Framework Programme (FP7/2007-2013)/ERC grant agreement number 256961.

The NOAA SEARCH program provided funding for the installation and operation of the P-AERI at Eureka from 2006 to 2009. Von P. Walden provided calibrated quality-controlled P-AERI data.

Penny M. Rowe acknowledges funding from FONDECYT Regular 1161460 and from the National Science Foundation under PLR 1543236.

Edited by: Gabriele Stiller

Reviewed by: three anonymous referees

\section{References}

ACIA: Arctic Climate Impact Assessment, Cambridge University Press, 1042 pp., 2005.

Adams, C., Strong, K., Batchelor, R. L., Bernath, P. F., Brohede, S., Boone, C., Degenstein, D., Daffer, W. H., Drummond, J. R., Fogal, P. F., Farahani, E., Fayt, C., Fraser, A., Goutail, F., Hendrick, F., Kolonjari, F., Lindenmaier, R., Manney, G., McElroy, C. T., McLinden, C. A., Mendonca, J., Park, J.-H., Pavlovic, B., Pazmino, A., Roth, C., Savastiouk, V., Walker, K. A., Weaver, D., and Zhao, X.: Validation of ACE and OSIRIS ozone and $\mathrm{NO}_{2}$ measurements using ground-based instruments at $80^{\circ} \mathrm{N}$, Atmos. Meas. Tech., 5, 927-953, https://doi.org/10.5194/amt-5927-2012, 2012.

Alexandrov, M. D., Schmid, B., Turner, D. D., Cairns, B., Oinas, V., Lacis, A. A., Gutman, S. I., Westwater, E. R., Smirnov, A., and Eilers, J.: Columnar water vapor retrievals from multifilter rotating shadowband radiometer data, J. Geophys. Res., 114, D02306, https://doi.org/10.1029/2008JD010543, 2009.

Antonelli, P., Revercomb, H. E., Sromovsky, L. A., Smith, W. L., Knuteson, R. O., Tobin, D. C., Garcia, R. K., Howell, H. B., Huang, H.-L., and Best, F. A.: A principal component noise filter for high spectral resolution infrared measurements, J. Geophys. Res., 109, D23102, https://doi.org/10.1029/2004JD004862, 2004.

Aumann, H. H., Chahine, M. T., Gautier, C., Goldberg, M., Kalnay, E., McMillin, L., Revercomb, H., Rosenkranz, P. W., Smith, W. L., Staelin, D., Strow, L., and Susskind, J.: AIRS/AMSU/HSB on the aqua mission: Design, science objectives, data products, and processing systems, IEEE T. Geosci. Remote, 41, 253-264, https://doi.org/10.1109/TGRS.2002.808356, 2003.

Barthlott, S., Schneider, M., Hase, F., Wiegele, A., Christner, E., González, Y., Blumenstock, T., Dohe, S., García, O. E., Sepúlveda, E., Strong, K., Mendonca, J., Weaver, D., Palm, M., Deutscher, N. M., Warneke, T., Notholt, J., Lejeune, B., Mahieu, E., Jones, N., Griffith, D. W. T., Velazco, V. A., Smale, D., Robinson, J., Kivi, R., Heikkinen, P., and Raffalski, U.: Us- 
ing $\mathrm{XCO}_{2}$ retrievals for assessing the long-term consistency of NDACC/FTIR data sets, Atmos. Meas. Tech., 8, 1555-1573, https://doi.org/10.5194/amt-8-1555-2015, 2015.

Barthlott, S., Schneider, M., Hase, F., Blumenstock, T., Kiel, M., Dubravica, D., García, O. E., Sepúlveda, E., Mengistu Tsidu, G., Takele Kenea, S., Grutter, M., Plaza-Medina, E. F., Stremme, W., Strong, K., Weaver, D., Palm, M., Warneke, T., Notholt, J., Mahieu, E., Servais, C., Jones, N., Griffith, D. W. T., Smale, D., and Robinson, J.: Tropospheric water vapour isotopologue data $\left(\mathrm{H}_{2}^{16} \mathrm{O}, \mathrm{H}_{2}^{18} \mathrm{O}\right.$ and $\left.\mathrm{HD}^{16} \mathrm{O}\right)$ as obtained from NDACC/FTIR solar absorption spectra, Earth Syst. Sci. Data, 9, 15-29, https://doi.org/10.5194/essd-9-15-2017, 2017.

Batchelor, R. L., Strong, K., Lindenmaier, R., Mittermeier, R. L., Fast, H., Drummond, J. R., and Fogal, P. F.: A new Bruker IFS 125HR FTIR spectrometer for the Polar Environment Atmospheric Research Laboratory at Eureka, Canada - measurements and comparison with the existing Bomem DA8 spectrometer, J. Atmos. Ocean. Tech., 26, 1328-1340, 2009.

Batchelor, R. L., Kolonjari, F., Lindenmaier, R., Mittermeier, R. L., Daffer, W., Fast, H., Manney, G., Strong, K., and Walker, K. A.: Four Fourier transform spectrometers and the Arctic polar vortex: instrument intercomparison and ACE-FTS validation at Eureka during the IPY springs of 2007 and 2008, Atmos. Meas. Tech., 3, 51-66, https://doi.org/10.5194/amt-3-51-2010, 2010.

Buehler, S. A., Östman, S., Melsheimer, C., Holl, G., Eliasson, S., John, V. O., Blumenstock, T., Hase, F., Elgered, G., Raffalski, U., Nasuno, T., Satoh, M., Milz, M., and Mendrok, J.: A multiinstrument comparison of integrated water vapour measurements at a high latitude site, Atmos. Chem. Phys., 12, 10925-10943, https://doi.org/10.5194/acp-12-10925-2012, 2012.

Clough, S., Iacono, M. J., and Moncet, J. L.: Line-by-line calculations of atmospheric fluxes and cooling rates: Application to water vapor, J. Geophys. Res.-Atmos., 97, 15761-15785, 1992.

Clough, S. A., Shephard, M. W., Mlawer, E. J., Delamere, J. S., Iacono, M. J., Cady-Pereira, K., Boukabara, S., and Brown, P. D.: Atmospheric radiative transfer modeling: a summary of the AER codes, J. Quant. Spectrosc. Ra., 91, 233-244, 2005.

Conway, T. J., Lang, P. M., and Masarie, K. A.: Atmospheric carbon dioxide dry air mole fractions from the NOAA ESRL Carbon Cycle Cooperative Global Air Sampling Network, 1968-2010, available at: ftp://aftp.cmdl.noaa.gov/data/trace_gases/co2/flask/ surface/, last access: 14 October 2011.

Dessler, A. E., Zhang, Z., and Yang, P.: Water vapor climate feedback inferred from climate fluctuations, 2003-2008, Geophys. Res. Lett., 35, L20704, https://doi.org/10.1029/2008GL035333, 2008.

Dirksen, R. J., Sommer, M., Immler, F. J., Hurst, D. F., Kivi, R., and Vömel, H.: Reference quality upper-air measurements: GRUAN data processing for the Vaisala RS92 radiosonde, Atmos. Meas. Tech., 7, 4463-4490, https://doi.org/10.5194/amt-7-4463-2014, 2014.

Feltz, W., Smith, W. L., Howell, H. B., Knuteson, R. O., Woolf, H., and Revercomb, H.: Near-continuous profiling of temperature, moisture, and atmospheric stability using the Atmospheric Emitted Radiance Interferometer (AERI), J. Appl. Meteorol., 42, 584-597, 2003.

Fogal, P., LeBlanc, L. M., and Drummond, J.: The Polar Environment Atmospheric Research Laboratory (PEARL): Sounding the Atmosphere at 80 North, Arctic, 66, 377-386, 2013.
Hase, F., Hannigan, J. W., Coffey, M. T., Goldman, A., Hopfner, M., Jones, N. B., Rinsland, C. P., and Wood, S.: Intercomparison of retrieval codes used for the analysis of high-resolution, groundbased FTIR measurements, J. Quant. Spectrosc. Ra., 87, 25-52, 2004.

Holben, B., Eck, T., Slutsker, I., Tanre, D., Buis, J., Setzer, A., Vermote, E., Reagan, J. A., Kaufman, Y. J., Nakajima, T., Lavenu, F., Jankowiak, I., and Smirnov, A.: AERONET - a federated instrument network and data archive for aerosol characterization, Remote Sens. Environ., 66, 1-16, 1998.

Hwang, Y -T. and Frierson, D. M. W.: Increasing atmospheric poleward energy transport with global warming, Geophys. Res. Lett., 37, L24807, https://doi.org/10.1029/2010GL045440, 2010.

Immler, F. J., Dykema, J., Gardiner, T., Whiteman, D. N., Thorne, P. W., and Vömel, H.: Reference Quality Upper-Air Measurements: guidance for developing GRUAN data products, Atmos. Meas. Tech., 3, 1217-1231, https://doi.org/10.5194/amt-3-1217-2010, 2010.

IPCC: Climate Change 2013: The Physical Science Basis, Contribution of Working Group I to the Fifth Assessment Report of the Intergovernmental Panel on Climate Change, edited by: Stocker, T. F., Qin, D., Plattner, G.-K., Tignor, M., Allen, S. K., Boschung, J., Nauels, A., Xia, Y., Bex, V., and Midgley, P. M., Cambridge University Press, Cambridge, United Kingdom and New York, NY, USA, 1535 pp., https://doi.org/10.1017/CBO9781107415324, 2013.

Knuteson, R. O., Revercomb, H. E., Best, F. A., Ciganovich, N. C., Dedecker, R. G., Dirkx, T. P., Ellington, S. C., Feltz, W. F., Garcia, R. K., Howell, H. B., Smith, W. L., Short, J. F., and Tobin, D. C.: Atmospheric Emitted Radiance Interferometer. Part I: Instrument Design, J. Atmos. Ocean. Tech., 21, 1763-1789, 2004a.

Knuteson, R. O., Revercomb, H. E., Best, F. A., Ciganovich, N. C., Dedecker, R. G., Dirkx, T. P., Ellington, S. C., Feltz, W. F., Garcia, R. K., Howell, H. B., Smith, W. L., Short, J. F., and Tobin, D. C.: Atmospheric Emitted Radiance Interferometer. Part II: Instrument Performance, J. Atmos. Ocean. Tech., 21, 1777-1776, 2004b.

Kurylo, M. J.: Network for the detection of stratospheric change (NDSC), Proceedings of SPIE. The International Society for Optical Engineering, Remote Sensing of Atmospheric Chemistry, 1491, 168-174, 1991.

Lesins, G., Duck, T. J., and Drummond, J. R.: Climate Trends at Eureka in the Canadian High Arctic, Atmos. Ocean, 48, 59-80, 2010.

Liljegren, J. C. and Lesht, B. M.: Measurements of integrated water vapor and cloud liquid water from microwave radiometers at the DOE ARM cloud and radiation testbed in the U.S. Southern Great Plains, paper presented at International Geoscience and Remote Sensing Symposium, IEEE, Lincoln, Nebr., https://doi.org/10.1109/IGARSS.1996.516767, 1996.

Lindenmaier, R., Strong, K., Batchelor, R. L., Bernath, P., Chabrillat, S. H., Chipperfield, M., Daffer, W. H., Drummond, J. R., Feng, W., Jonsson, A. I., Kolonjari, F., Manney, G. L., McLinden, C. A., Menard, R., and Walker, K. A.: A study of the Arctic NOy budget above Eureka, Canada, J. Geophys. Res., 116, D23302, https://doi.org/10.1029/2011JD016207, 2011.

Lindenmaier, R., Strong, K., Batchelor, R. L., Chipperfield, M. P., Daffer, W. H., Drummond, J. R., Duck, T. J., Fast, H., Feng, W., Fogal, P. F., Kolonjari, F., Manney, G. L., Manson, A., 
Meek, C., Mittermeier, R. L., Nott, G. J., Perro, C., and Walker, K. A.: Unusually low ozone, $\mathrm{HCl}$, and $\mathrm{HNO}_{3}$ column measurements at Eureka, Canada during winter/spring 2011, Atmos. Chem. Phys., 12, 3821-3835, https://doi.org/10.5194/acp12-3821-2012, 2012.

Mariani, Z., Strong, K., Wolff, M., Rowe, P., Walden, V., Fogal, P. F., Duck, T., Lesins, G., Turner, D. S., Cox, C., Eloranta, E., Drummond, J. R., Roy, C., Turner, D. D., Hudak, D., and Lindenmaier, I. A.: Infrared measurements in the Arctic using two Atmospheric Emitted Radiance Interferometers, Atmos. Meas. Tech., 5, 329-344, https://doi.org/10.5194/amt-5329-2012, 2012.

Mariani, Z., Strong, K., Palm, M., Lindenmaier, R., Adams, C., Zhao, X., Savastiouk, V., McElroy, C. T., Goutail, F., and Drummond, J. R.: Year-round retrievals of trace gases in the Arctic using the Extended-range Atmospheric Emitted Radiance Interferometer, Atmos. Meas. Tech., 6, 1549-1565, https://doi.org/10.5194/amt-6-1549-2013, 2013.

McClatchey, R. A., Fenn, R. W., Selby, J. E. A., Volz, F. E., and Garing, J. S.: Optical properties of the atmosphere, 3rd Edn. Tech. Rep. AFCRL-72-0497, Air Force Geophysical Laboratories, 108 pp., 1972.

Miloshevich, L., Vömel, H., Whiteman, D., and Leblanc, T.: Accuracy assessment and correction of Vaisala RS92 radiosonde water vapor measurements, J. Geophys. Res., 114, D11305, https://doi.org/10.1029/2008JD011565, 2009.

Mlawer, E. J., Payne, V. H., Moncet, J. -L., Delamere, J. S., Alvarado, M. J., and Tobin, D. C.: Development and recent evaluation of the MT_CKD model of continuum absorption, Philos. T. R. Soc. A, 370, 1-37, https://doi.org/10.1098/rsta.2011.0295, 2012.

Palm, M., Melsheimer, C., Noël, S., Heise, S., Notholt, J., Burrows, J., and Schrems, O.: Integrated water vapor above $\mathrm{Ny}$ Ålesund, Spitsbergen: a multi-sensor intercomparison, Atmos. Chem. Phys., 10, 1215-1226, https://doi.org/10.5194/acp-101215-2010, 2010.

Pérez-Ramírez, D., Whiteman, D. N., Smirnov, A., Lyamani, H., Holben, B., Pinker, R., Andrade, M., and AladosArboledas, L.: Evaluation of AERONET precipitable water vapor versus microwave radiometry, GPS and radiosondes at ARM sites, J. Geophys. Res.-Atmos., 119, 9596-9613, https://doi.org/10.1002/2014JD021730, 2014.

Rodgers, C. D.: Inverse methods for atmospheric sounding: theory and practice, World Scientific Publishing Co., Singapore, ISBN 981-02-2740-X, 2000.

Rodgers, C. and Connor, B.: Intercomparison of remote sounding instruments, J. Geophys. Res., 108, 4116, https://doi.org/10.1029/2002JD00229, 2003.

Rowe, P. M.: Measurements of the foreign-broadened continuum of water vapor in the 6.3 micron band at -30 Celsius, $\mathrm{PhD}$ thesis, Department of Chemistry, University of Washington, 2004.

Rowe, P. M., Walden, V. P., and Warren, S. G.: Measurements of the foreign-broadened continuum of water vapor in the $6.3 \mu \mathrm{m}$ band at $-30{ }^{\circ} \mathrm{C}$, Appl. Opt., 45, 4366-4382. https://doi.org/10.1364/AO.45.004366, 2006.

Rowe, P. M., Miloshevich, L. M., Turner, D. S., and Walden, V. P.: Dry Bias in Vaisala RS90 radiosonde humidity profiles over Antarctica, J. Atmos. Ocean. Tech., 25, 1529-1541, 2008.
Rowe, P. M., Neshyba, S. P., and Walden, V. P.: Responsivity-based criterion for accurate calibration of FTIR emission spectra: theoretical development and bandwidth estimation, Opt. Express, 19, 5451-5463, 2011.

Schneider, M., Romero, P. M., Hase, F., Blumenstock, T., Cuevas, E., and Ramos, R.: Continuous quality assessment of atmospheric water vapour measurement techniques: FTIR, Cimel, MFRSR, GPS, and Vaisala RS92, Atmos. Meas. Tech., 3, 323 338, https://doi.org/10.5194/amt-3-323-2010, 2010.

Schneider, M., Barthlott, S., Hase, F., González, Y., Yoshimura, K., García, O. E., Sepúlveda, E., Gomez-Pelaez, A., Gisi, M., Kohlhepp, R., Dohe, S., Blumenstock, T., Wiegele, A., Christner, E., Strong, K., Weaver, D., Palm, M., Deutscher, N. M., Warneke, T., Notholt, J., Lejeune, B., Demoulin, P., Jones, N., Griffith, D. W. T., Smale, D., and Robinson, J.: Groundbased remote sensing of tropospheric water vapour isotopologues within the project MUSICA, Atmos. Meas. Tech., 5, 3007-3027, https://doi.org/10.5194/amt-5-3007-2012, 2012.

Schneider, M., González, Y., Dyroff, C., Christner, E., Wiegele, A., Barthlott, S., García, O. E., Sepúlveda, E., Hase, F., Andrey, J., Blumenstock, T., Guirado, C., Ramos, R., and Rodríguez, S.: Empirical validation and proof of added value of MUSICA's tropospheric $\mathrm{dD}$ remote sensing products, Atmos. Meas. Tech., 8, 483-503, https://doi.org/10.5194/amt-8-483-2015, 2015.

Schneider, M., Wiegele, A., Barthlott, S., González, Y., Christner, E., Dyroff, C., García, O. E., Hase, F., Blumenstock, T., Sepúlveda, E., Mengistu Tsidu, G., Takele Kenea, S., Rodríguez, S., and Andrey, J.: Accomplishments of the MUSICA project to provide accurate, long-term, global and high-resolution observations of tropospheric $\mathrm{H}_{2} \mathrm{O}$, dD pairs - a review, Atmos. Meas. Tech., 9, 2845-2875, https://doi.org/10.5194/amt-9-2845-2016, 2016.

Serreze, M. C., Barrett, A. P., and Stroeve, J.: Recent changes in tropospheric water vapor over the Arctic as assessed from radiosondes and atmospheric reanalyses, J. Geophys. Res., 117, D10104, https://doi.org/10.1029/2011JD017421, 2012.

Sheese, P. E., Walker, K. A., Boone, C. D., Bernath, P. F., Froidevaux, L., Funke, B., Raspollini, P., and von Clarmann, T.: ACE-FTS ozone, water vapour, nitrous oxide, nitric acid, and carbon monoxide profile comparisons with MIPAS and MLS, J. Quant. Spectrosc. Ra., 186, 63-80, https://doi.org/10.1016/j.jqsrt.2016.06.026, 2016.

Shindell, D. T.: Climate and ozone response to increased stratospheric water vapor, Geophys. Res. Lett., 28, 1551-1554, 2001.

Sioris, C. E., Zou, J., McElroy, C. T., McLinden, C. A., and Vömel, H.: High vertical resolution water vapour profiles in the upper troposphere and lower stratosphere retrieved from MAESTRO solar occultation spectra, Adv. Space Res., 46, 642-650, 2010.

Smirnov A., Holben, B. N., Eck, T. F., Dubovik, O., and Slutsker, I.: Cloud screening and quality control algorithms for the AERONET data base, Rem. Sens. Env., 73, 337-349, 2000.

Smirnov, A., Holben, B. N., Lyapustin, A., Slutsker, I., and Eck, T. F.: AERONET processing algorithm refinement, AERONET Workshop, El Arenosillo, Spain, 10-14 May, 2004.

Soden, B. J., Wetherald, R. T., Stenchikov, G. L., and Robock, A.: Global cooling after the eruption of Mount Pinatubo: a test of climate feedback by water vapor, Science, 26, 727-730, 2002.

Stevens, B. and Bony, S.: What are climate models missing? Science, 340, 1053-1054, 2013. 
Steinke, S., Eikenberg, S., Löhnert, U., Dick, G., Klocke, D., Di Girolamo, P., and Crewell, S.: Assessment of smallscale integrated water vapour variability during HOPE, Atmos. Chem. Phys., 15, 2675-2692, https://doi.org/10.5194/acp-152675-2015, 2015.

Sussmann, R., Borsdorff, T., Rettinger, M., Camy-Peyret, C., Demoulin, P., Duchatelet, P., Mahieu, E., and Servais, C.: Technical Note: Harmonized retrieval of column-integrated atmospheric water vapor from the FTIR network - first examples for longterm records and station trends, Atmos. Chem. Phys., 9, 89878999, https://doi.org/10.5194/acp-9-8987-2009, 2009.

Tobin, D. C., Best, F. A., Brown, P. D., Clough, S. A., Dedecker, R. G., Ellingson, R. G., Garcia, R. K., Howell, H. B., Knuteson, R. O., Mlawar, E. J., Revercomb, H. E., Short, J. F., van Delst, P. F. W., and Walden, V. P.: Downwelling spectral radiance observations at the SHEBA ice station: Water vapor continuum measurements from 17 to $26 \mu \mathrm{m}$, J. Geophys. Res., 104, 2081-2092, 1999.

Trenberth, B. J., Wetherald, R. T., Stenchikov, G. L., and Robock, A.: Global cooling after the eruption of Mount Pinatubo: a test of climate feedback by water vapor, Science, 296, 727-730, 2002.

Trenberth, K. E., Dai, A., van der Schrier, G., Jones, D. P., Barichivich, J., Briffa, K. R., and Sheffield, J.: Global warming and changes in drought, Nature Climate Change, 4, 17-22, 2013.

Trenberth, K. E.: Challenges for Observing and Modeling the Global Water Cycle, in Remote Sensing of the Terrestrial Water Cycle, edited by: Lakshmi, V., Alsdorf, D., Anderson, M., Biancamaria, S., Cosh, M., Entin, J., Huffman, G., Kustas, W., van Oevelen, P., Painter, T., Parajka, J., Rodell, M., and Rüdiger, C., John Wiley and Sons, Inc., Hoboken, NJ, 2014.
Turner, D. D., Knuteson, R. O., Revercomb, H., Lo, C., and Dedecker, R. G.: Noise reduction of Atmospheric Emitted Radiance Interferometer (AERI) observations using principal component analysis, J. Atmos. Ocean. Tech., 23, 1223-1238, 2006.

Viatte, C., Strong, K., Hannigan, J., Nussbaumer, E., Emmons, L. K., Conway, S., Paton-Walsh, C., Hartley, J., Benmergui, J., and Lin, J.: Identifying fire plumes in the Arctic with tropospheric FTIR measurements and transport models, Atmos. Chem. Phys., 15, 2227-2246, https://doi.org/10.5194/acp-152227-2015, 2015.

Vömel, H., Selkirk, H., Miloshevich, L., Valverde-Canossa, J., Valdes, J., Kyrö, E., Kivi, R., Stolz, W., Peng, G., and Diaz, J.: Radiation dry bias of the Vaisala RS92 humidity sensor, J. Atmos. Ocean. Tech., 24, 953-963, 2007.

Westwater, E. R., Han, Y., Shupe, M. D., and Matrosov, S. Y.: Analysis of integrated cloud liquid and precipitable water vapor retrievals from microwave radiometers during the Surface Heat Budget of the Arctic Ocean project, J. Geophys. Res., 106, 32019-32030, 2001.

Wexler, A.: Vapor pressure formulation for water in range 0 to $100^{\circ} \mathrm{C}$ : A revision, J. Res. Natl. Bur. Stand., 80A, 775-785, 1976.

World Meteorological Organization (WMO): The Global Observing System for Climate: Implementation Needs, wmo.int, available at: https://library.wmo.int/opac/doc_num.php?explnum_id= 3417 (last access: 6 July 2017), 2016.

World Meteorological Organization (WMO): Details for Variable: Integrated Water Vapour (IWV), Wmo-sat.info, available at: https://www.wmo-sat.info/oscar/variables/view/162, last access: 28 June 2017. 